\title{
ADMINISTRATIVE CREATIVITY IN PROBLEM SOLVING AND ITS RELATIONSHIP TO JOB SATISFACTION AMONG PRINCIPALS OF POST BASIC EDUCATION SCHOOLS IN THE NORTH AL-BATINAH GOVERNORATE IN THE SULTANATE OF OMAN

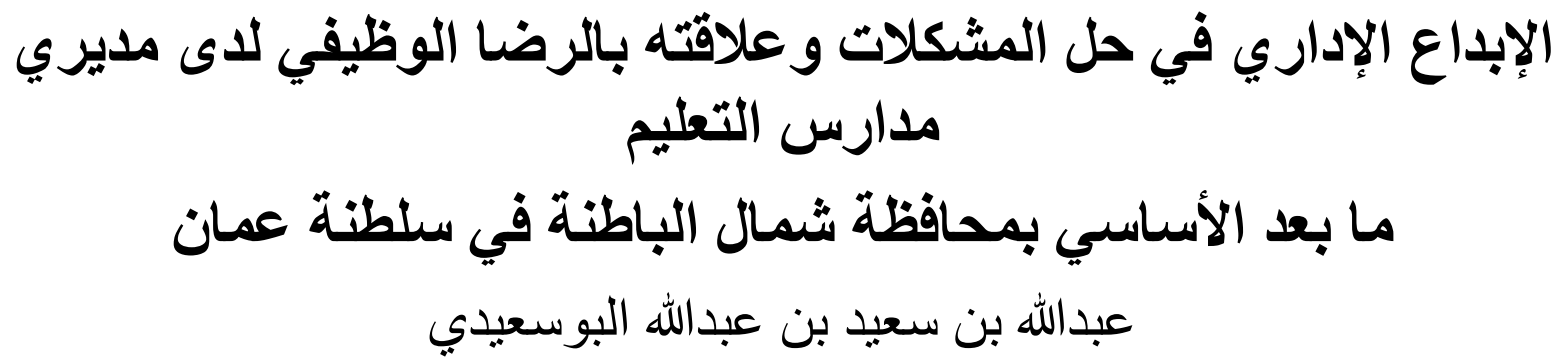

\section{Abdullah Saidabdullah Albousaidi ${ }^{1 \star}$, Prof. Dr. Mohd Burhan Ibrahim² and Prof. Dr. Ismaiel Hassanien ${ }^{3}$}

${ }^{1} \mathrm{Ph} . \mathrm{D}$. Candidate at the Faculty of Educationi International Islamic University Malaysia (IIUM); Abdullah.saeed1001@gmail.com

\author{
${ }^{2}$ Prof. Dr. at the Faculty of Education, International Islamic University Malaysia (IIUM); \\ mburhan.@iium.edu.my \\ ${ }^{3}$ Prof. Dr. at the Faculty of Education, International Islamic University Malaysia (IIUM); tulib5@ \\ iium.edu.my \\ ${ }^{*}$ Corresponding Author
}

\begin{abstract}
This quantitative study aims to identify administrative creativity and its strategies' role in solving problems and determining its relationship to job satisfaction among principals of North Al Batinah governorate schools in the Sultanate of Oman. The problem lies in confirming studies that school principals lack the desire and educational experience, which hinders their ability to lead change and the weak elements of creativity and experience in their schools. The researcher adopted the descriptive approach in his study, through a (52) statements questionnaire, distributed in (3) axes are: problems, administrative creativity and job satisfaction. The study population included (141) principals, and a random sample of (39) principals was chosen. The data were analyzed by descriptive analysis method, and Pearson Correlation Coefficient. The study reached several results, including: that there is a positive correlation at the level of significance (0.05) between the level of managers' use of creative methods in solving problems and the level of job satisfaction of employees, also showed a positive correlation at the level of significance $(0.05)$ between the level of managers use of methods Management of organizational conflict and the level of employee satisfaction.
\end{abstract}

Keywords: creative thinking, problem solving, job satisfaction.

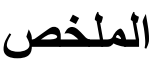

تهدف هذه الدراسة الكمية إلى التعرف على الإبداع الإداري واستراتيجياته، ودوره في حل 
المشكلات وتحديد علاقته بالرضا الوظيفي، لدى مديري مدارس محافظة شمال الباطنة بسلطنة

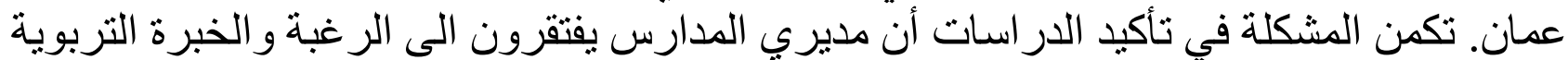
مما يعيق قدر اتهم على قيادة التغير وضعف عناصر الأبداع و الخبرة في مدارسهم. اعتمد الباحث المنهج الوصفي في دراسته, بواسطة أداة البحث الرئيسة وهي الاستبيان, حيث تم تصميم استبانة لهذا الغرض, تكونت من (52) عبارة توزعت في (3) محاور هي: المشكلات و الإبداع الإداري

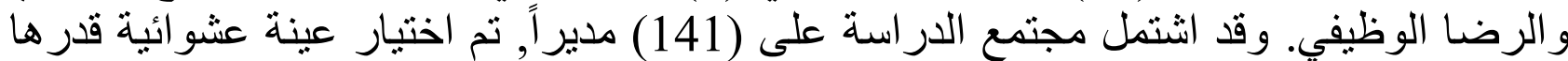
(39) مدير ا. تم تحليل البيانات من خلال منهج التحليل الوصفي، ومعامل ارتباط بيرسون. وقد التها توصلت الدراسة إلى نتائج عدة منها: أن هنالك علاقة ارتباطية موجبة عند مستوى دلالة (0.05) بين مستوى استخدام المدراء لأساليب إبداعية في حل المشكلات ومستوى الرضات الرهات الوظيفي للموظفين، كما بينت وجود علاقة ارتباطية موجبة عند مستوى دلالة (0.05) بين مستوى استخدام

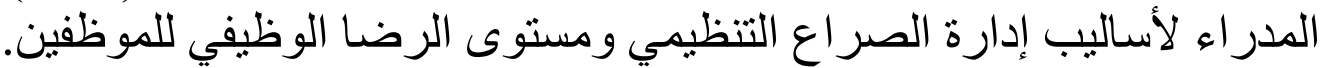
كلمات مفتاحية: التفكير الإبداعي، حل المشكلات، الرضا الوظيفي.

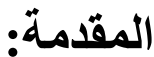

يعد التفكير الإبداعي و البناء مدخل أساسيا لتطوير المنظمات وبقائها وهو من المهار ات الأساسية

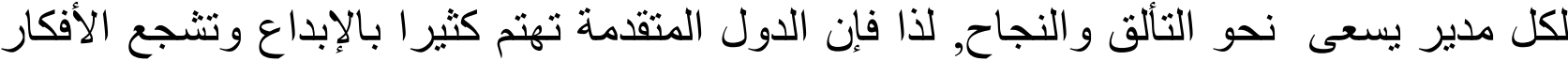
المبتكرة وتدعمها لتحقيق مستويات عالية من الرفاهية و التطوير لثعوبها و الازدهار لاقتصادها. فأصبحت الحاجة للأفكار المبتكرة ضرورة ملحة تفرضها التغيرات السياسية والاقتصادية

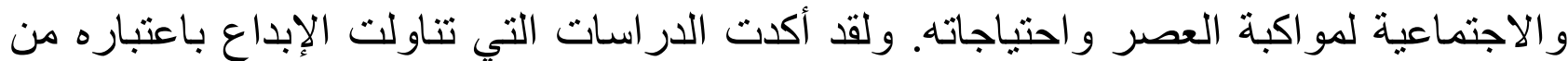
المهار ات الأساسية والضرورية لكل مدير يسعى للنجاح والتميز والتهية والتخلص من الروتين السائد وأنماط السلوك الإداري الإسئه المعتاد .

عرف جروان (1425 هـ) الإبداع بأنه: مزيج من القدرات و الاستعدادات و الخصائص الثخصبة

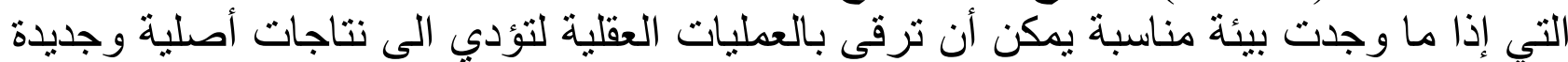

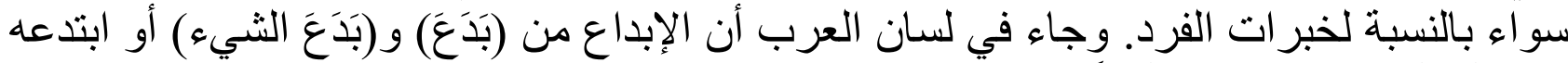

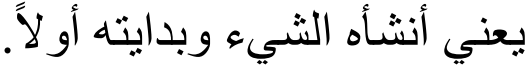
والإبداع في المعجم الوسيط هو من بدعه بدعاً أي أنشأه على غير مثال و(بدع) صار غاية في صنعته، خيراً كان أو شراً. و الابتداعية تتسم بالخروج في الأساليب القديمة عن طريق استخدام

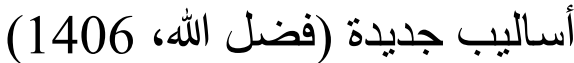
ويعرف الباحث الإبداع إجر ائبا: قدرة مدير المدرسة على تتظيم أفكاره و استخدام مجموعة من فن التصور ات و المفاهيم بأسلوب بناء و مبتكر في مو اجهة سائر التحديات في بيئته.

مفهوم الإباداع الإداري:

بعتبر الإبداع شكلاً من أشكال النشاط الإنساني. وقد ظل هذا الموضوع لفترة طويلة محور آ للتناول

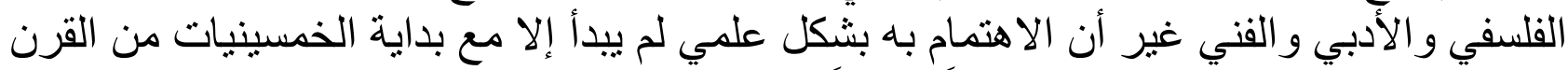
العشرين حيث كان الإبداع موضوعاً رئيساً في علم النفس. وقد ارنبط موضوع الإبداع في هي إني 
الماضي بالمنافسة بين الدول الغربية أثناء الحرب العالمية الثانية. أما في عصرنا الحاضر فقدان التانية ارتبط بالتسابق التقني بين الدول في مختلف المجالات الثناء الدهان، 1992م: 177).

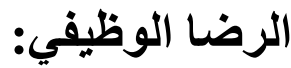

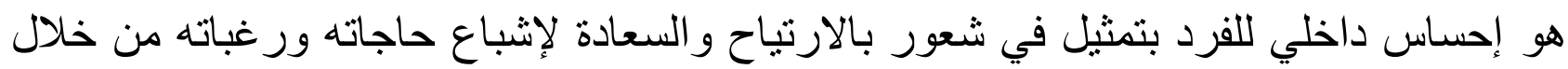

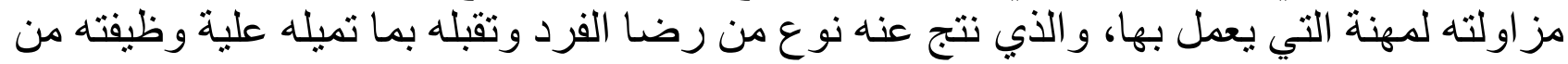

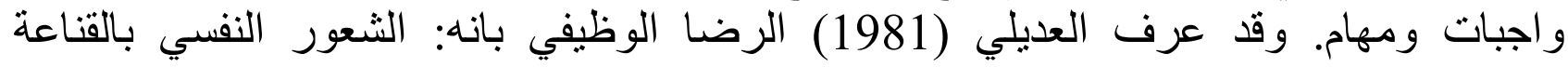

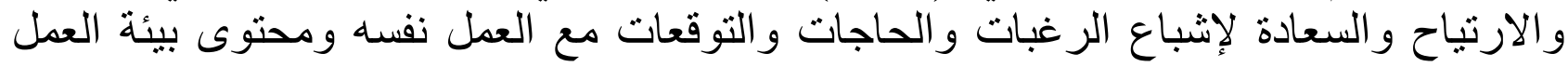

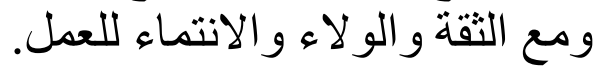

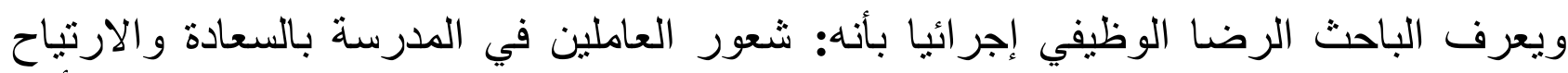

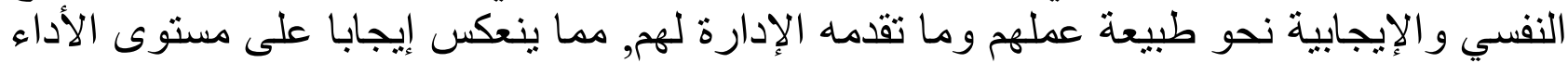
و الإنجاز لديهر.

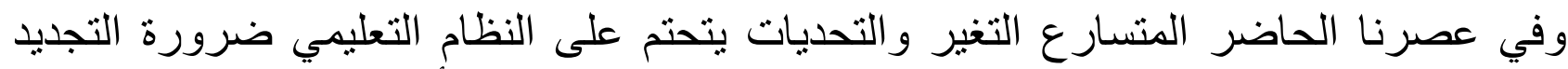

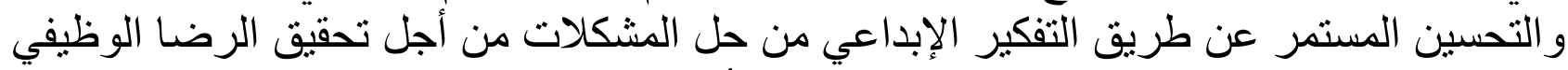

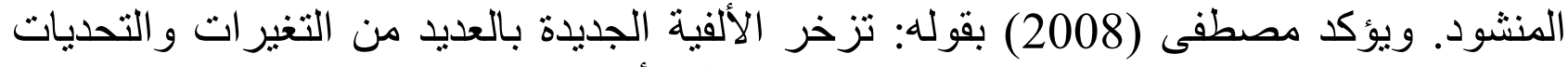

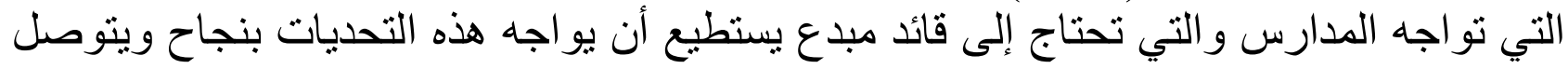
إلى حلول ومقترحات مبتكرة إز ائها.

إننا عندما نعتمد النمط الإبداعي في التفكير كثقافة مؤسسية فاعلة فإننا نستطيع بذللك حل وكو اجهة

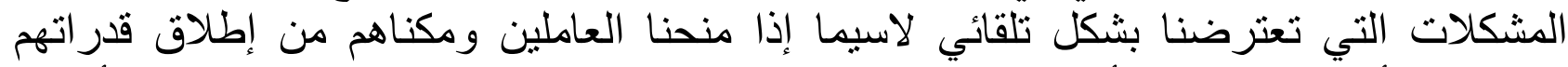

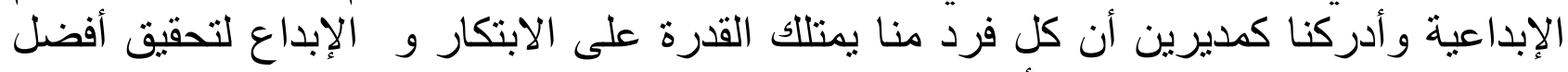

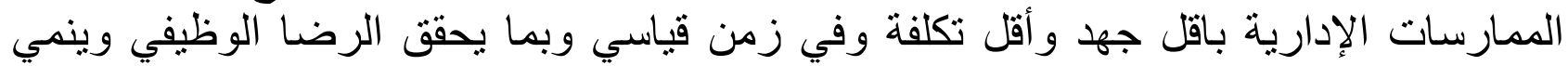

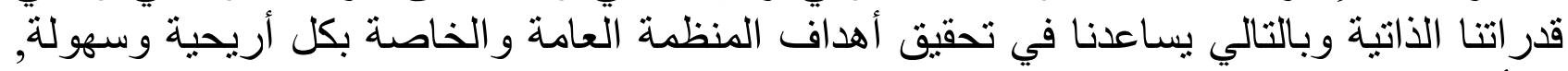

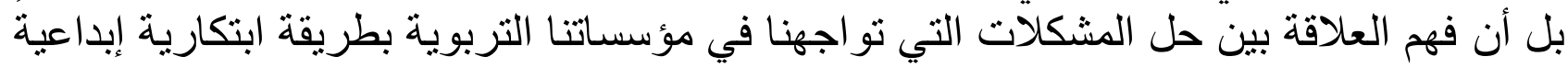

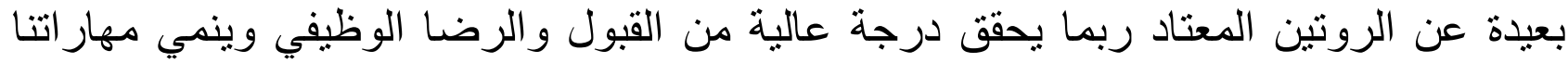

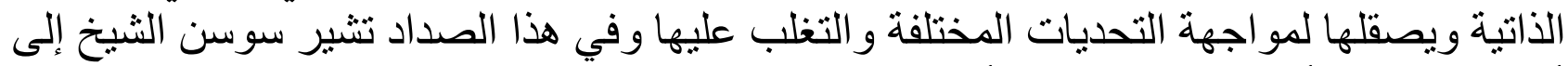

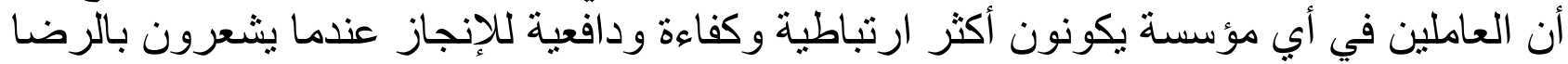

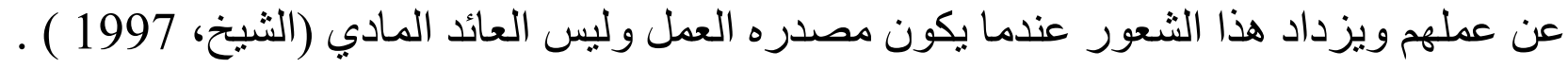

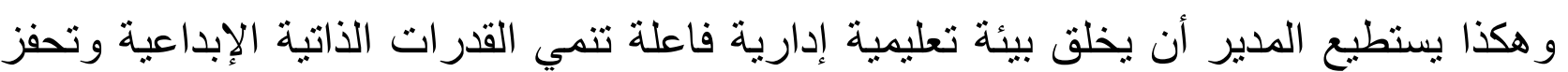

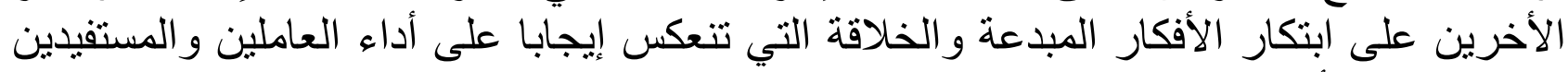

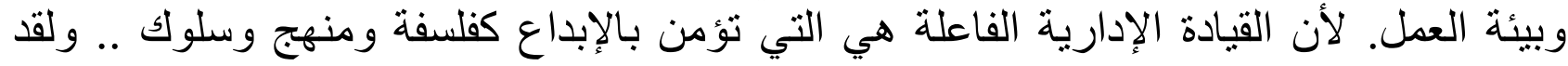

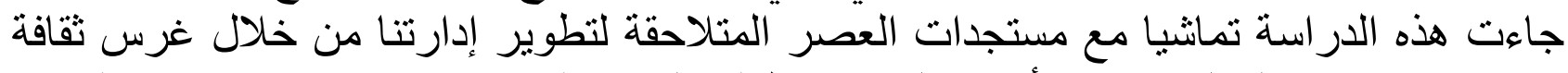

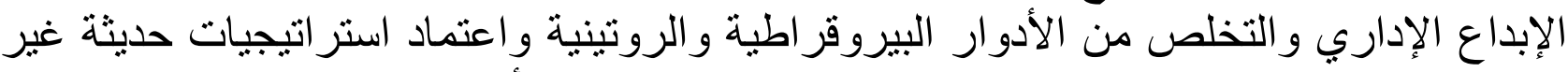

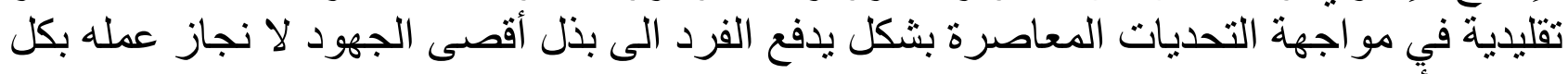
رضى وأَريحية.

وبهذا يصبح نجاح سائر المؤسسات مرهوناً بوجود المديرين المبدعين الذين يستطيعون إدارة

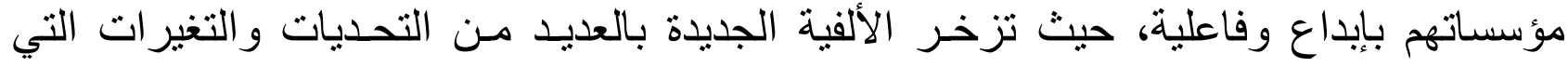


تو اجه المدارس والتي تحتاج إلى قائد مبدع يستطع أن يواجه هذه التحدئ التحديات, لتحقيق الأهداف

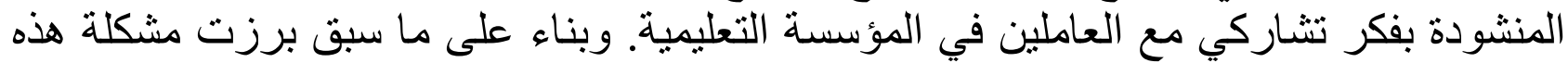

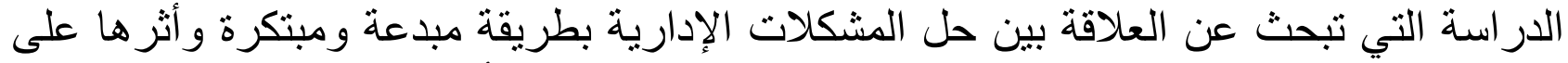

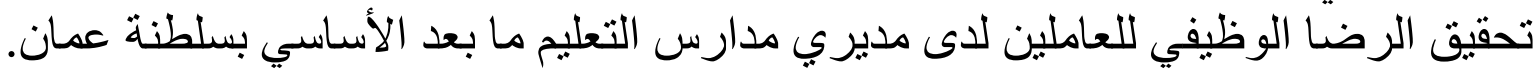

مشكلة الاراسة:

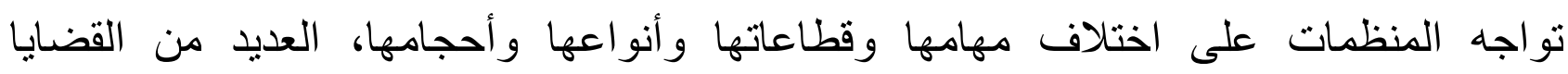

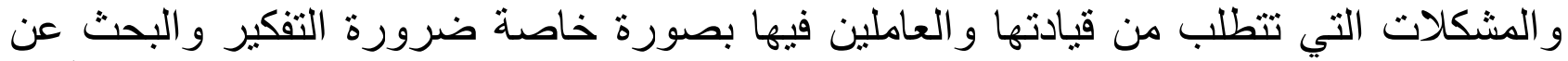

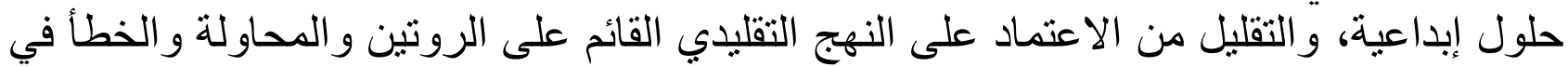
حل المشكلات، ومحاولة توظيف المنهج الإبداعي في هذا الثأن الناد (هيجان، 1402).

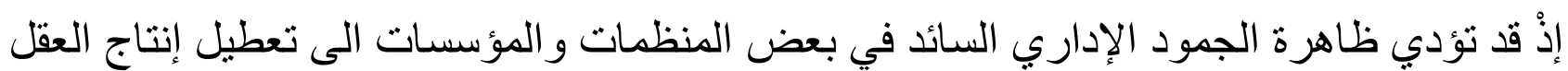

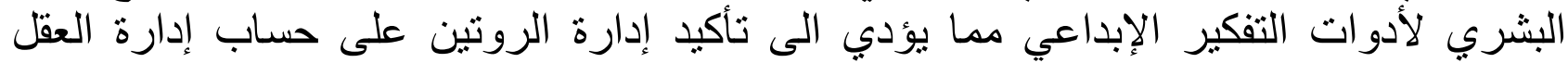

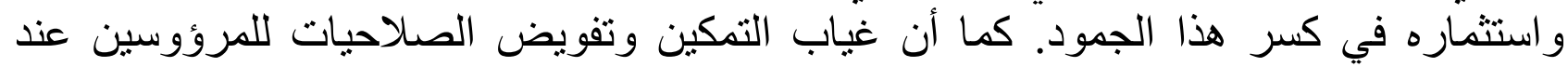

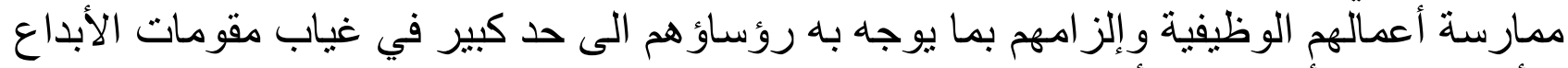
وتأكيد نمطية الأعمال مما أدى الى تز ايد المشكلات وتر اجع جودة الخمار الخدمات المقدمة للمستفيدين.

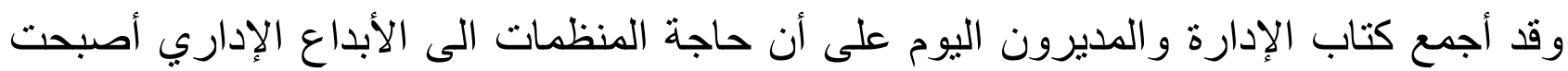

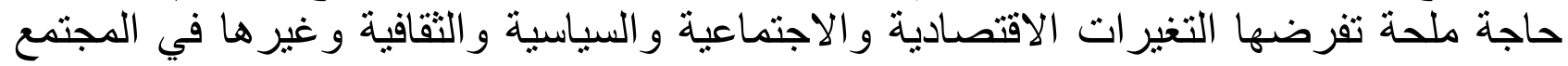

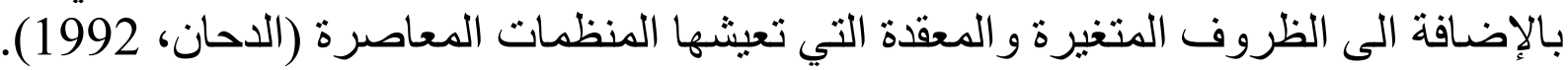

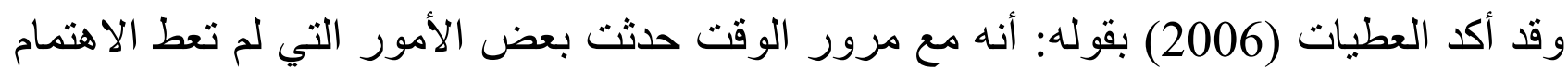

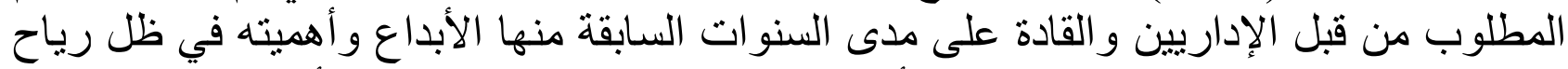

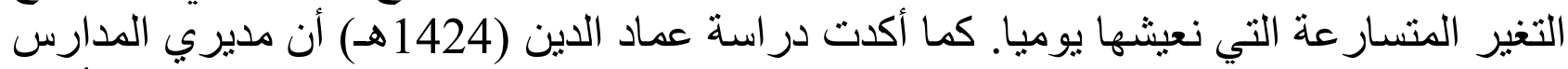

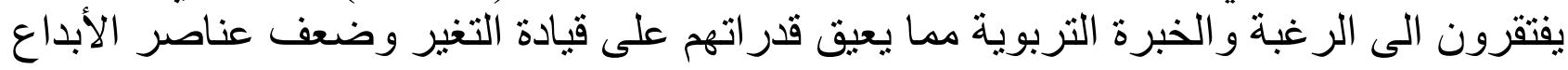
والخبرة في مدارسهم.

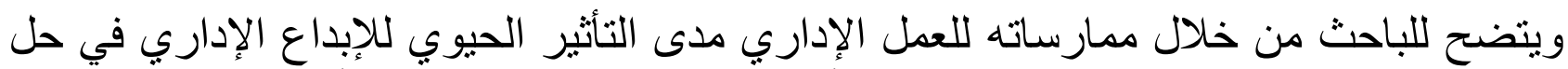

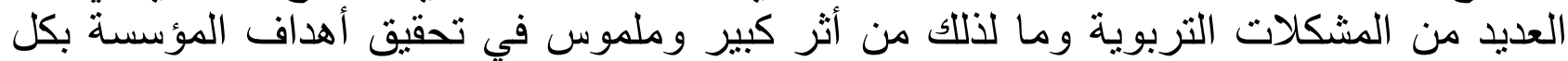

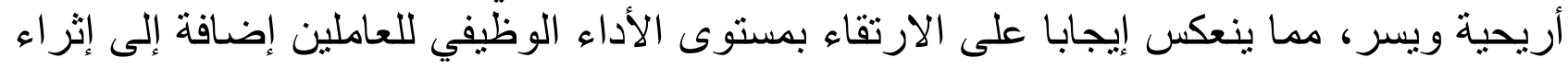
المعرفة العلمية في هذا المجال.

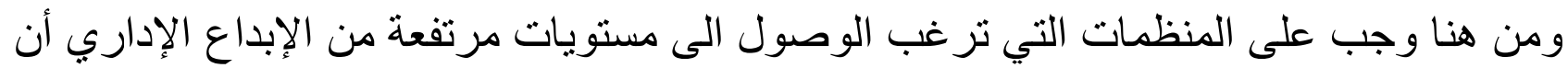

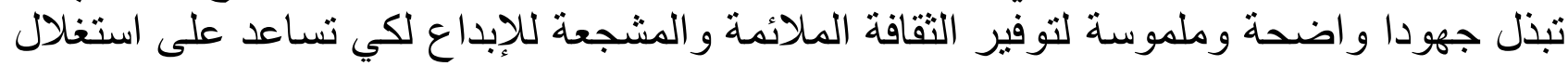

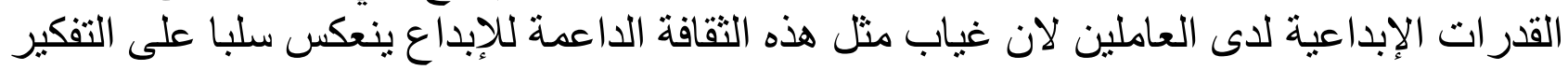

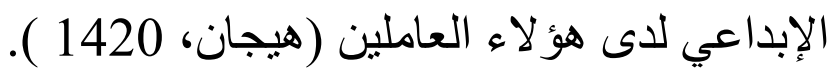

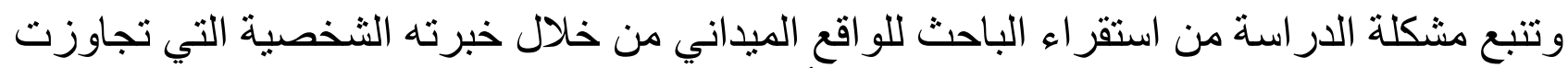

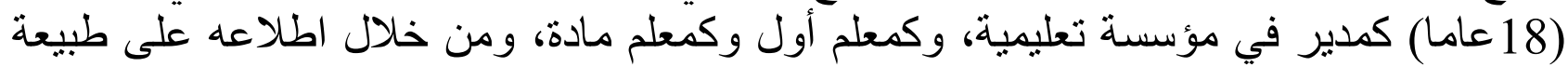

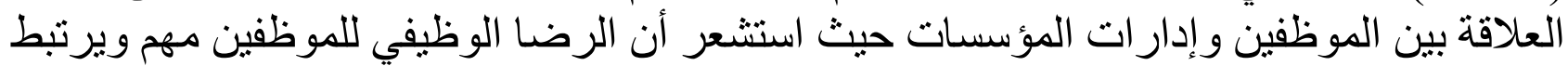

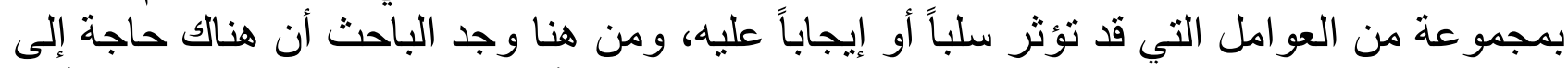

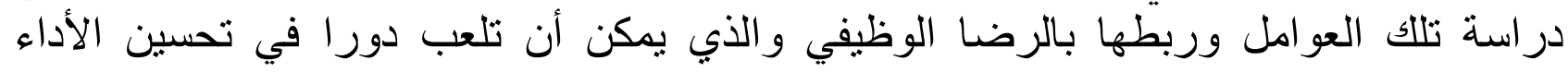


المؤسسي،

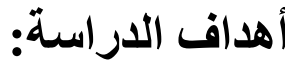

أ. تشخيص مستويات المشكلات في المدارس الحكومية و الخاصة بمحافظة شمال الباطنة بسلطنة

عمان. (- مان.

ب. مناقتنة مدى اتباع المدراء لأساليب إدارية مبدعة في حل مشكلات مدارس التعليم ما بعد الأساسي في محافظة شمال الباطنة بسلطنة عمان.

ت. تشخيص مستوى الرضا الوظيفي لاى مدراء مدارس التعليم ما بعد الأساسي في محافظة شمال الباطنة بسلطنة عمان.

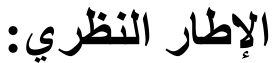

\section{المحور الأول: الإبداع الإداري:}

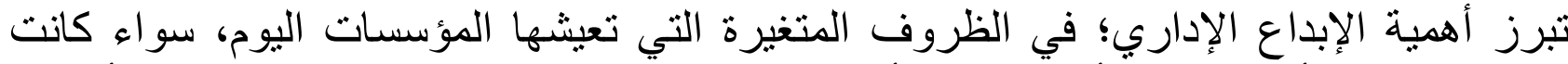

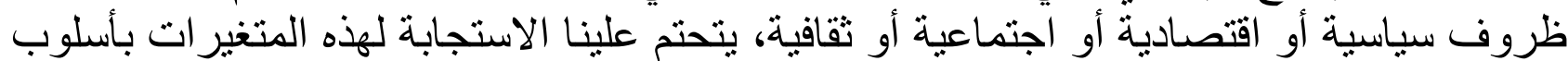

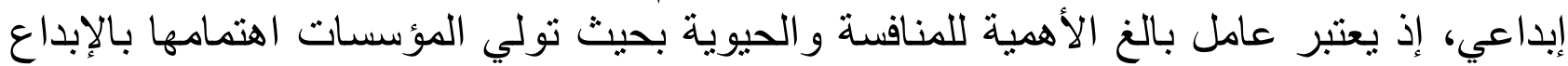

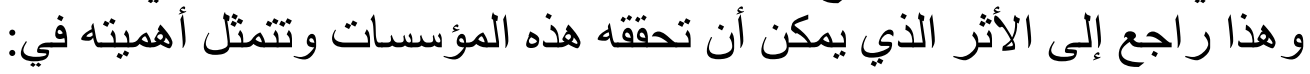

أ. إن الإبداع يقود إلى التجديد والتطوير المستمر مما يساعد المؤسسات خاصة الإنتاجية منها على تحقيق البقاء و التنافس في السوق السوقد

ب. يساعد الإبداع على دعم التنمية الاقتصادية من خلال إيجاد الأساليب و التقنيات و التكنولوجيا الملائمة الداعمة للتنمية.

ت. يساعد على إيجاد الحلول للمشكلات الخارجية والداخلية لتي تو اجهها المؤسسات، ويساهم

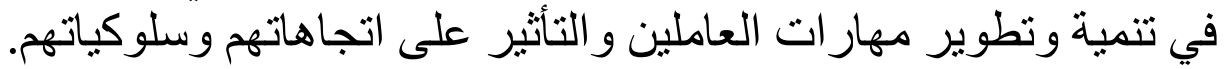

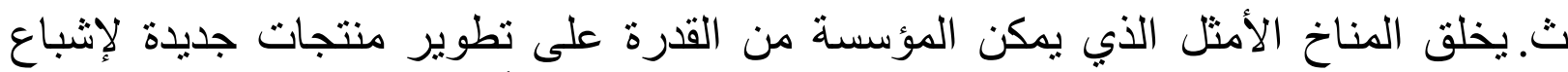

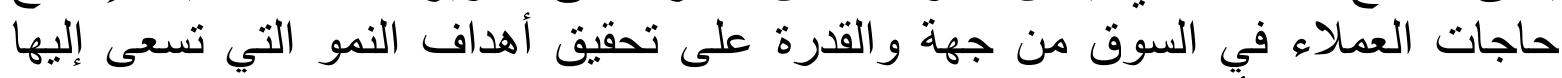

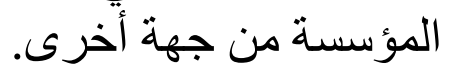

ج. يساعد المؤسسة في العمل بصورة أفضل من خلال تحسين الرقابة والتنسيق الداخلي

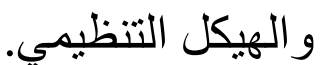

ح. يؤدي إلى تسهيل العمليات الإدارية التي تمكن المؤسسة من الاستمرار ومواصلة الصية عملها

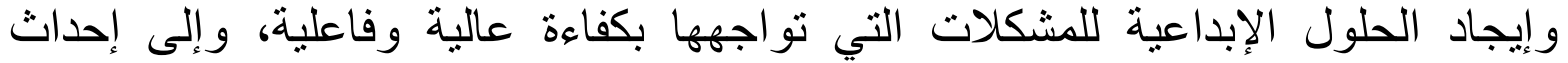
تغيير ات إيجابية في بناء المؤسسة.

خ. يساعد المؤسسة على التفاعل التكيف ومع كافة المتغيرات التئهاء البيأية المحيطة، وتحسين إنتاجيتها، و الارتقاء بمسنوى أدائها و أداء العاملين بها.

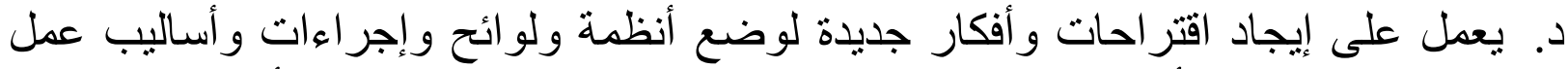

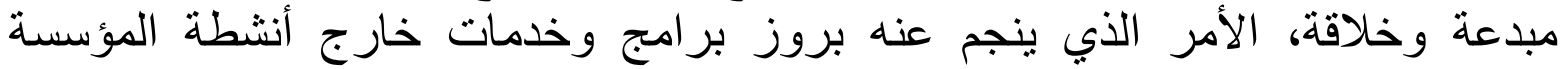


الرئيسية.

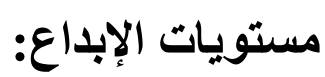

يرى العديد من الباحثين أن الإبداع ينقسم إلى مستويات عدة، تبدأ من تنظيم الأمور الحياتية وصو لاًاً

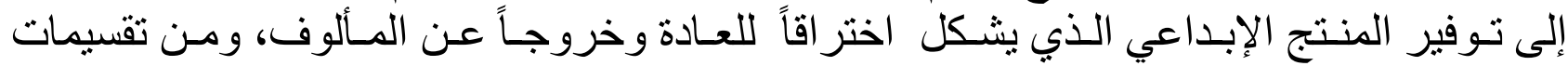

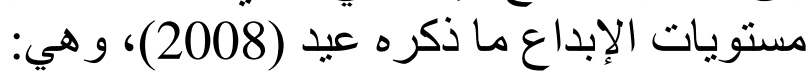

1. الإبداع التعبيري: الإبداع هنا صفة تلقائية، وغالباً ما يكون الإبـأ المبدع من هذا النوع في مجالات

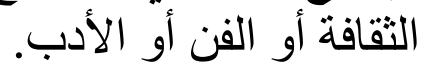

2. الإبداع المنتج أو التقني: يثير هذا النوع من الإبداع الإداري إلى قدرة الإداري إلى التوصل التوصل

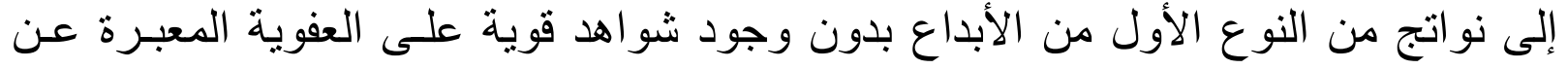
هذه النواتج.

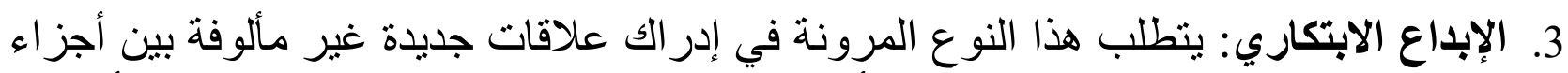

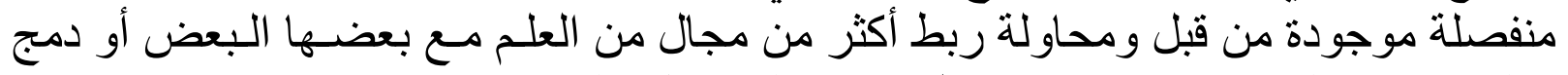

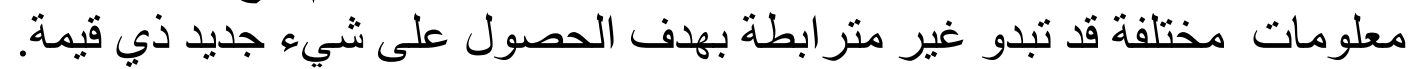

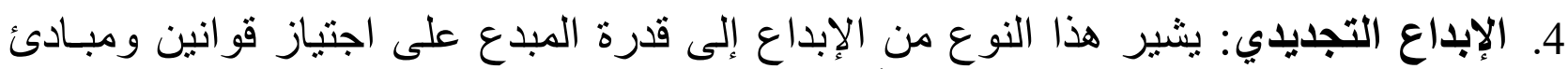

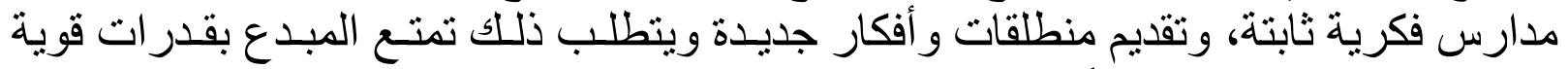

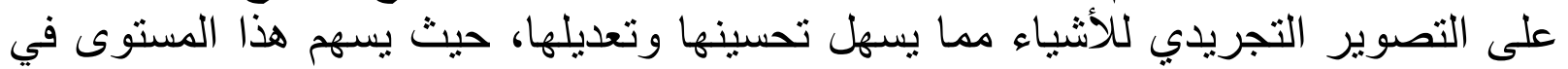

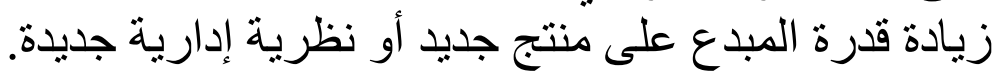

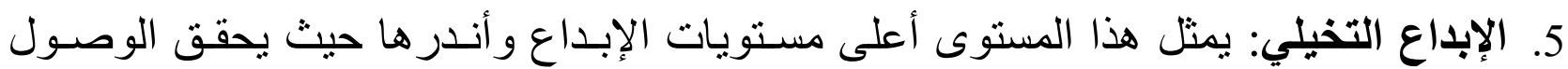

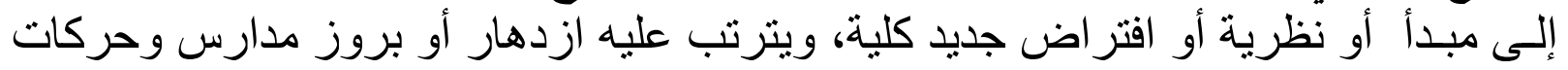

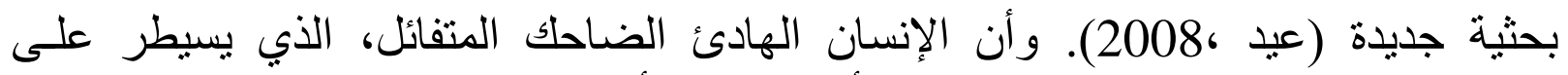

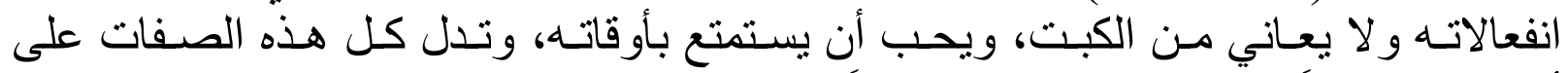

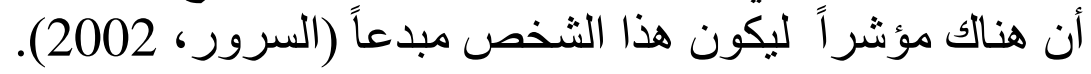

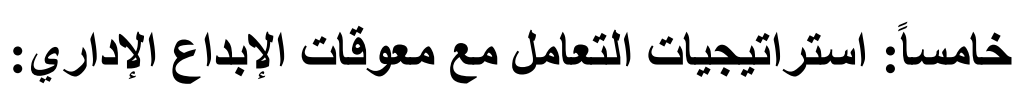

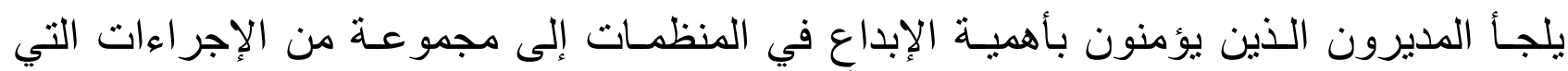

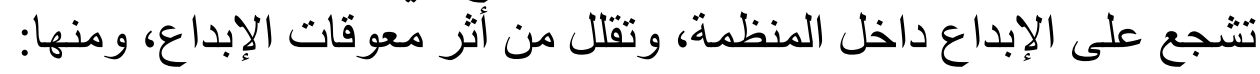
أ. تشجيع الأفر اد على التعبير عن أفكار هم بحرية. ب. تقديم الدعم فيما يتعلق بتطوير الأفكار الإبداعية. ت. ت تشجيع الأف ارد على المخاطرة. ث. إتاحة الخصوصية للأفر اد للتفكير الإبداعي.

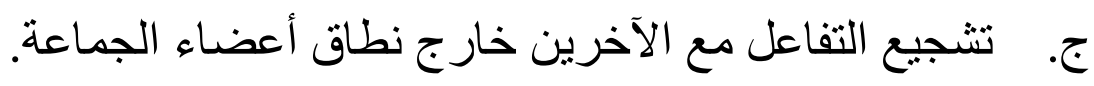

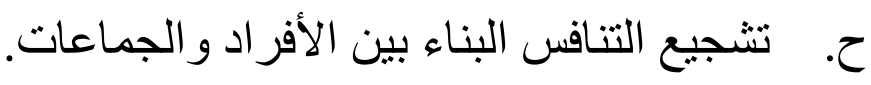

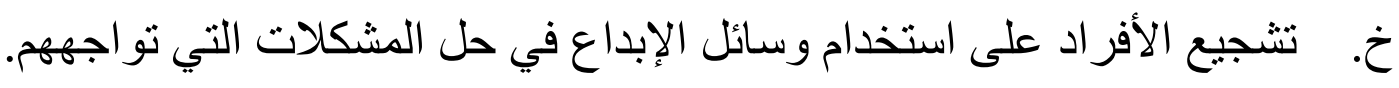


د. الحد من الإشر اف المفرط على الأف راد و الجماعات أثناء تأدية مهامهر.

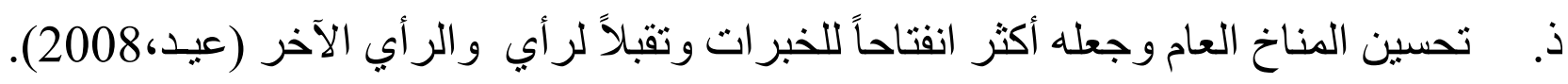

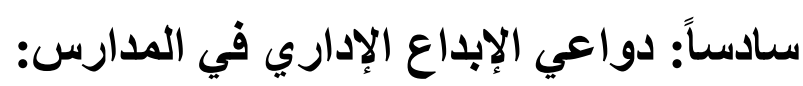

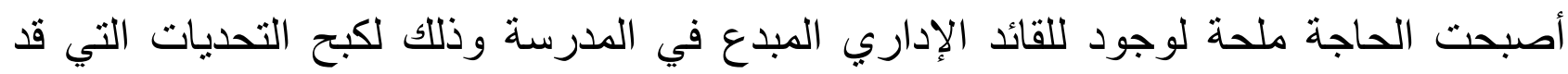

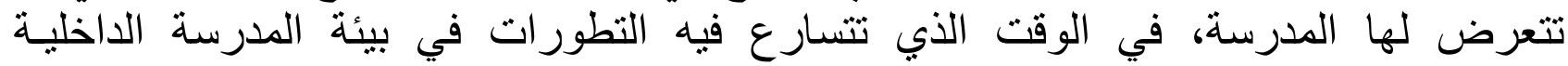

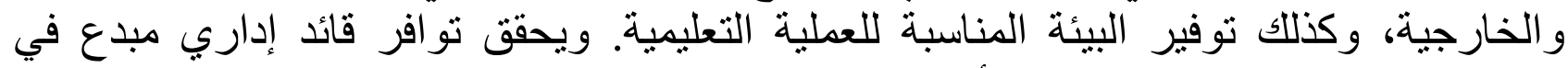

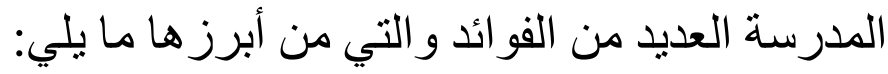

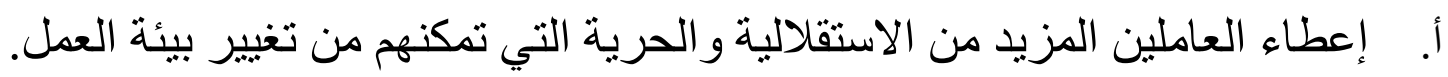
ب. حث العاملين على التفكير بطريقة خلاقة وحثهم على مواجهة الأخطار.

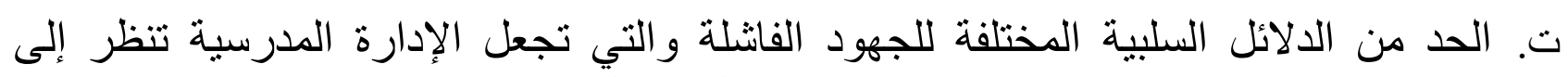

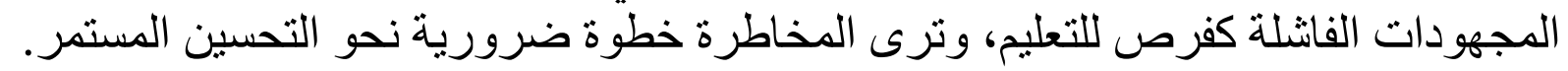

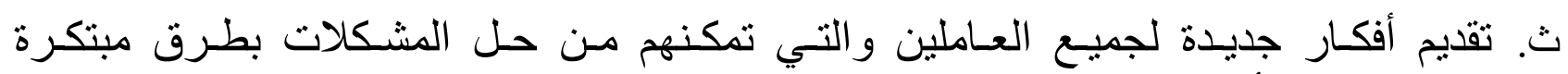

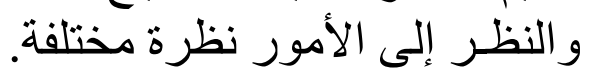

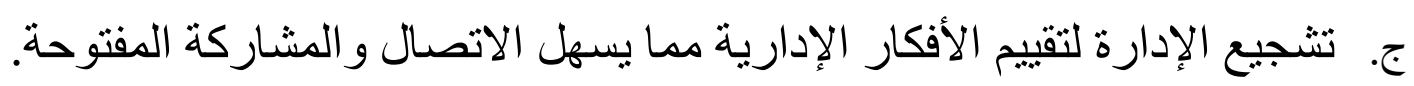

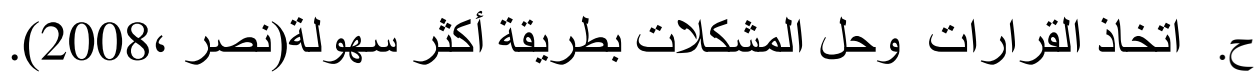

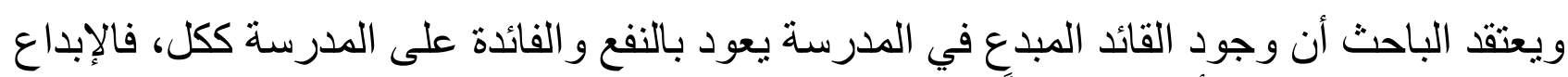

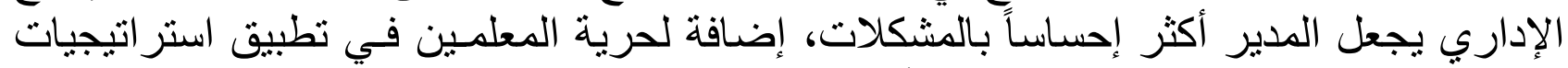

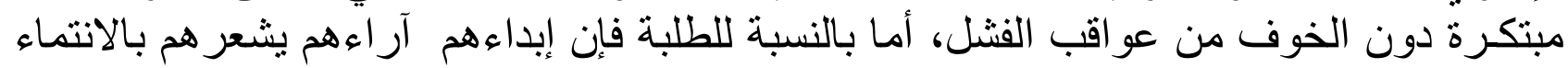
للمدرسـة و العملـل على المحافظة على على كيانها ونظامها. المحور الثاني: الرضا الوظيفي

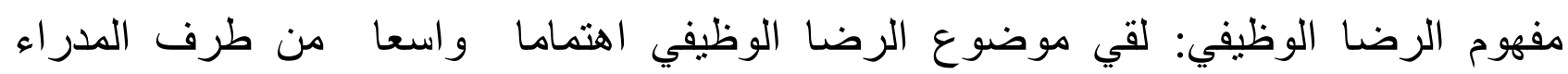

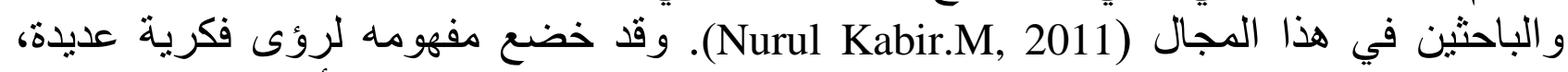

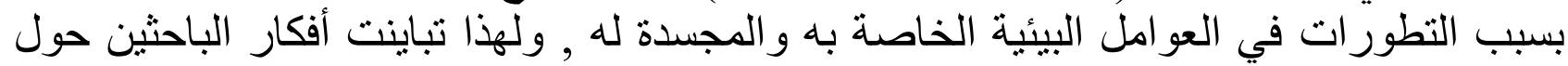

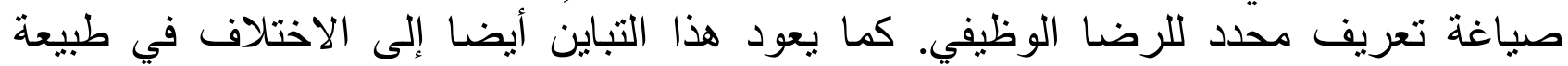

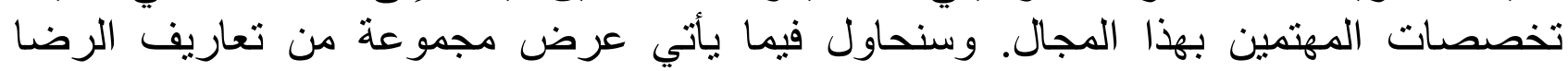

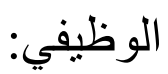

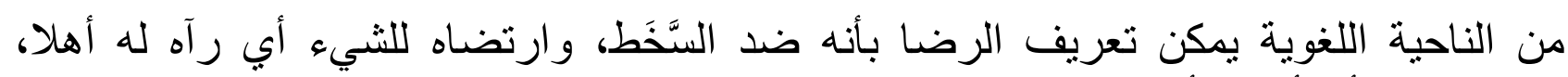

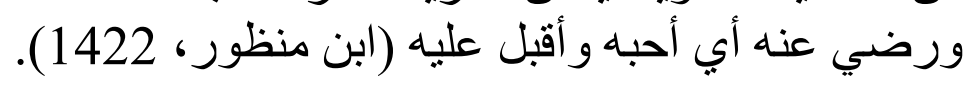

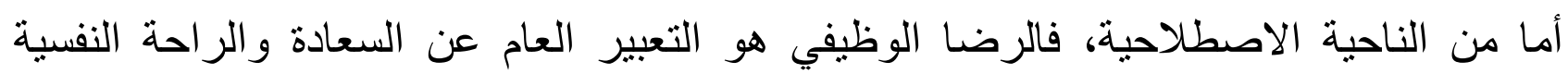

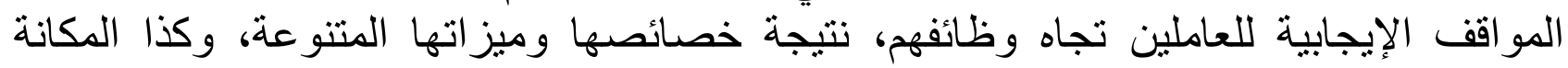
الاجتماعية التي تحصلو ا عليها و الخبر ات التئ التي اكتسبو ها من عملهم. 


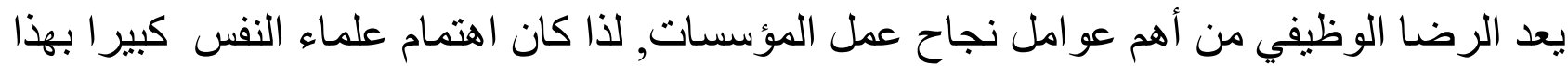

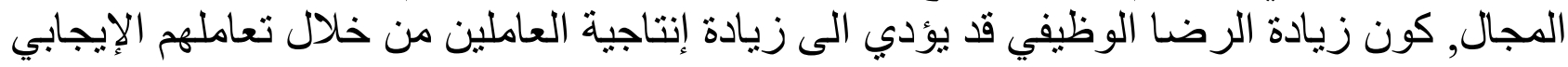

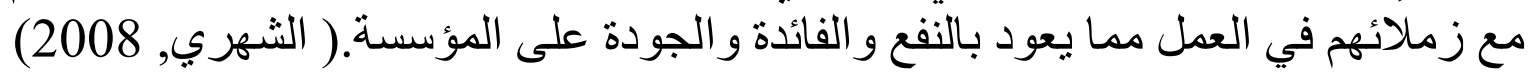
وقد قسم (نور الدين, 2005) الرضا الوظيفي إلى قسمين: الأول- بالنسبة للمؤسسة: فإنه يحقق المزايا الآتية

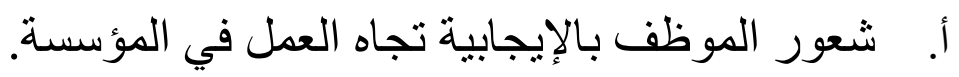
ب. ب. ارتفاع مستوى الفعالية. ت. ت. ارتفاع مستوى الإنتاجية. ث. تخفيض تكاليف الإنتاج. ج. ارتفاع مستوى الولاء للمؤسسة.

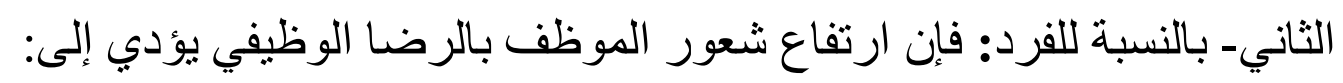

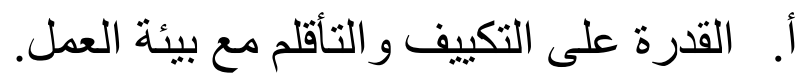
ب. الرغبة في الإبداع و الابتكار.

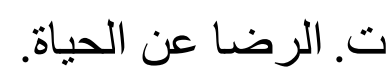

العوامل المؤثرة في الرضا الوظيفي: حدد شاويش, (2011) تللك العو امل المؤثرة كما يأتي:

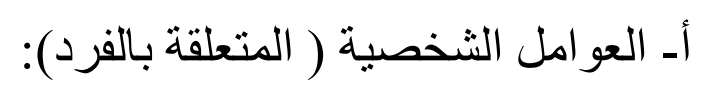

- حاجات الفرد: اذا حقق العمل إثباع لحاجات الفرد , كان مستوى الرضا لـان عال.

$$
\text { ـ ـ الشعور باحتر ام للذات. }
$$

ـ مستوى الإنجاز لاى الفرد: طموح الفرد وما يحققه من إنجاز.

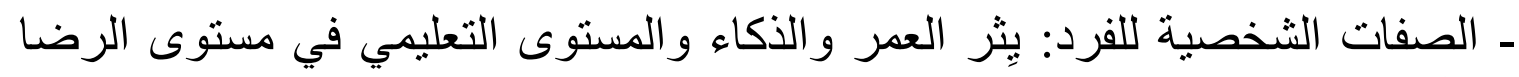
الوظيفي للفرد. ـ ـو افق العمل مع قيم الفرد: فكلما حقق العمل القيم الموجودة لدى الفرد, كلما زاد رضاه الوظيفي. بـ العو امل المتعلقة بالوظيفة:

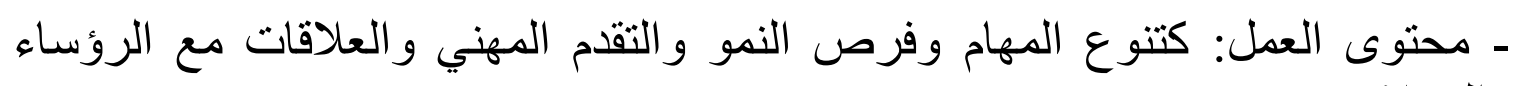
و والزملاء. متوى. ـ العو امل الخاصة بالإداء: كثُعور الفرد بأهمية العمل , وجود نظام مكافآت عادل. ـ تمكين العاملين: لتقديم أفضل ما لديهم من أداء.

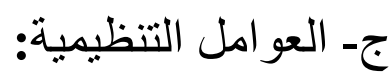

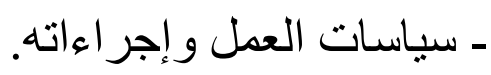


ـ - الهيكل التنظيمي.

ـ نمط القيادة و الإشر اف. ـوهيبة, 2010).

الاراسات السابقة:

أولاً: الدارسات المتعلقة بالإبداع الإداري:

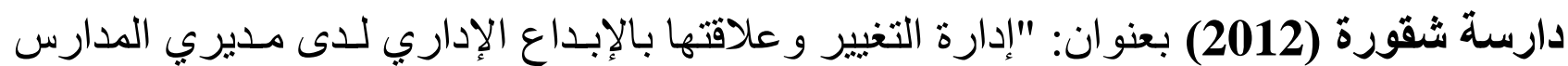

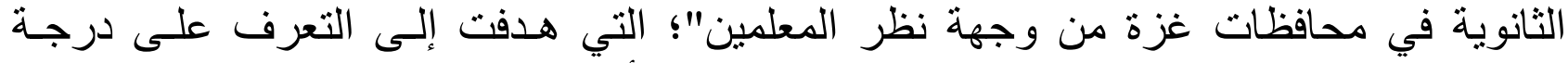

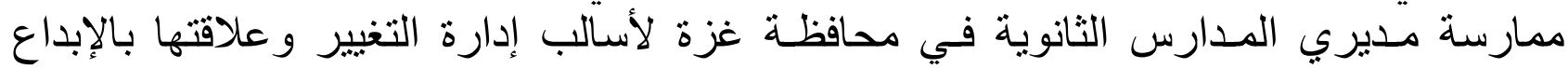
الإداري من وجهة نظر المعلمين.

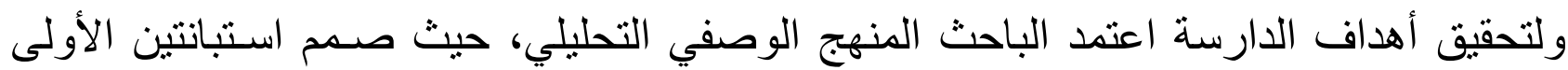

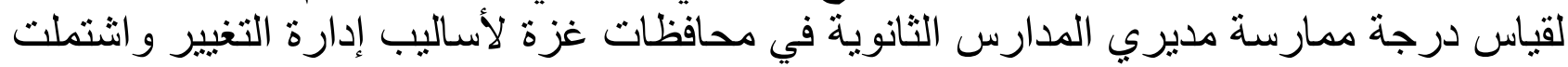

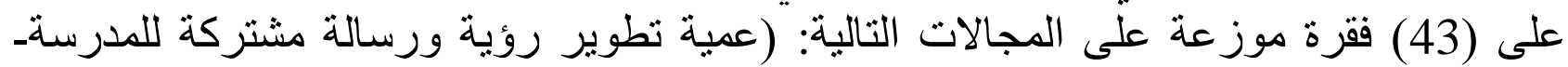

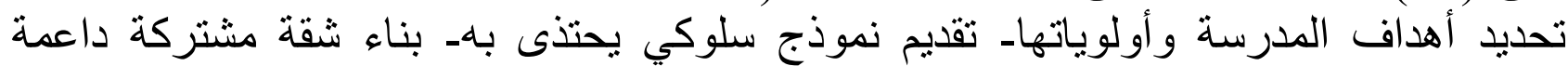

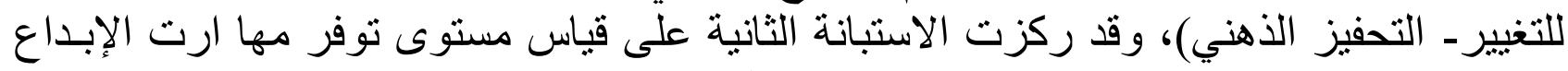

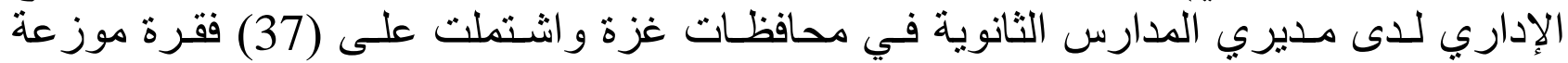

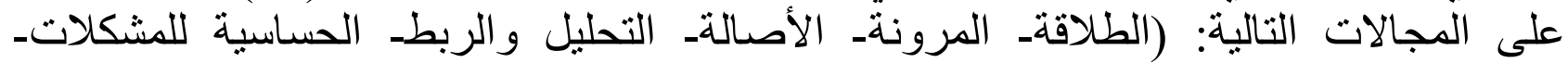

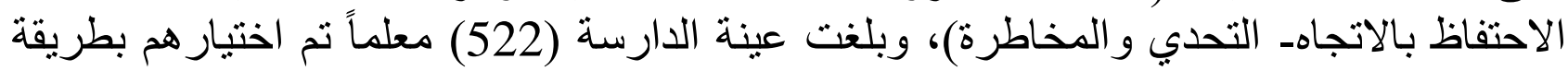
العينة العشو ائية الطبقية.

وتوصلت الدارسة إلى أن درجة ممارسة مديري المدارس الثانوية في محافظات غزة الإنهات الإدارة

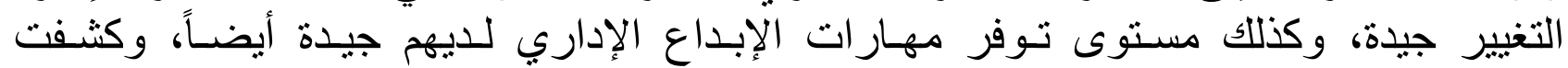

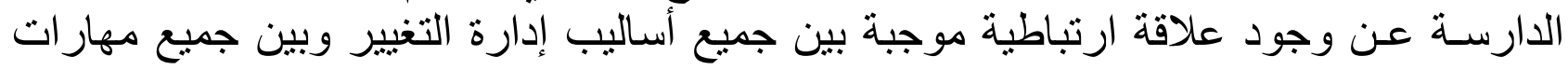
الإبداع الإداري.

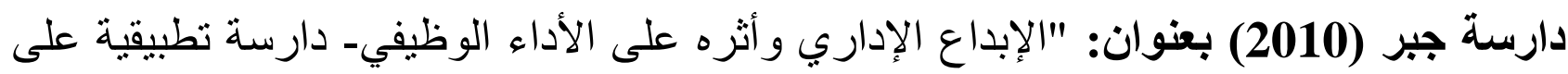

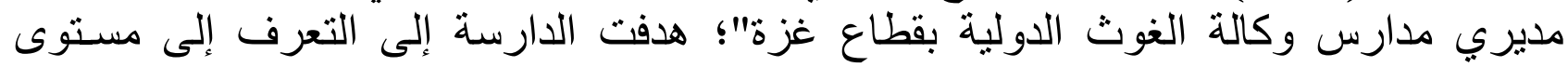

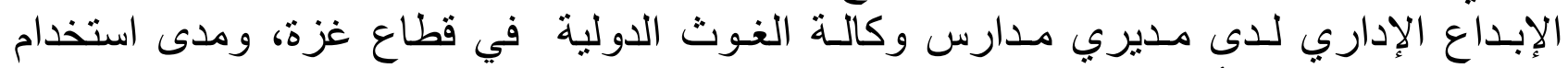

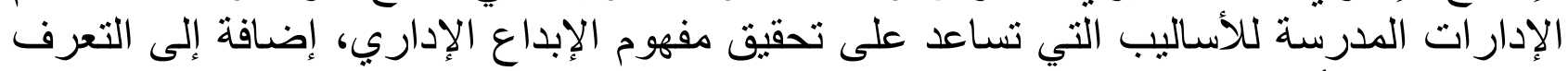

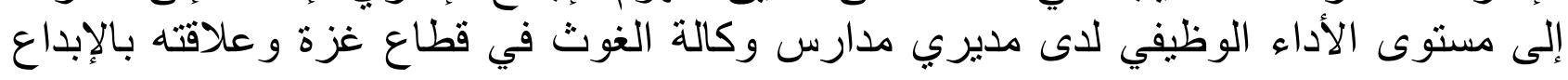
الإداري.

ولتحقيق أهداف الدارسة اعتمد الباحث في دراسته المنهج الوصفي التحليلي، حيث قام الباحث

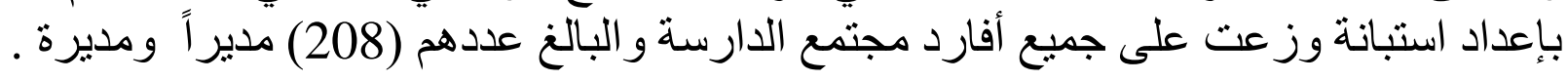

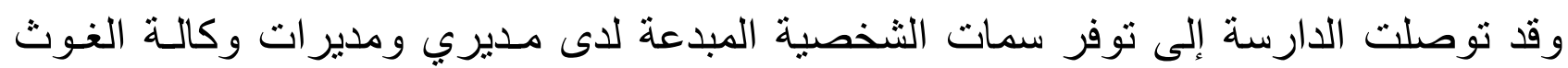

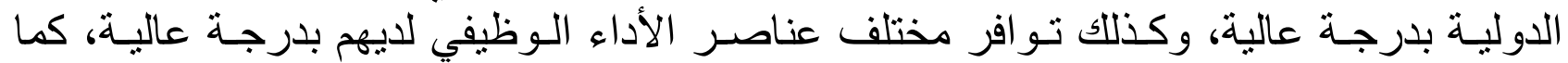

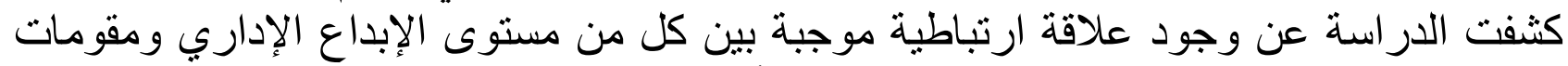

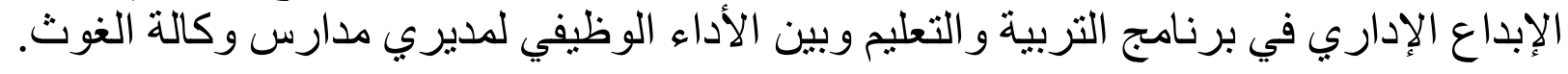

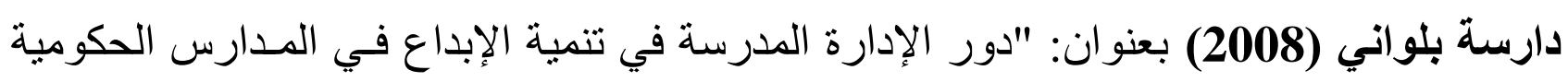


في محافظات شمال فلسطين ومعيقاتها من وجهة نظر مديريها"؛ وقد هدفت التعرف إلى دور

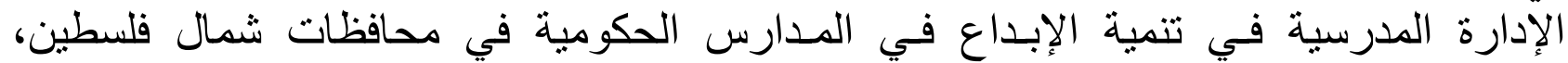

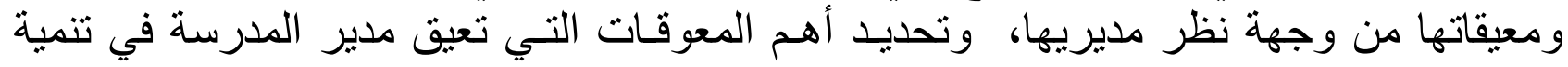

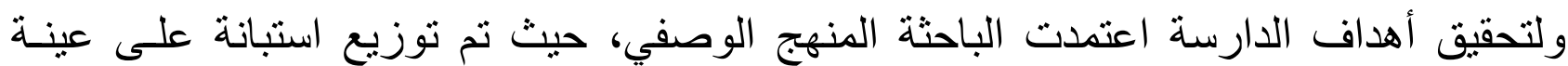

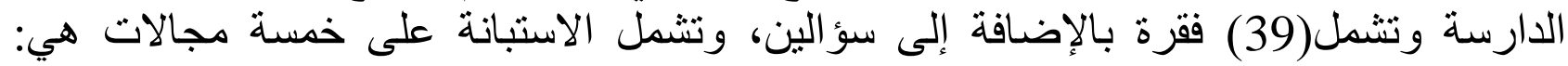

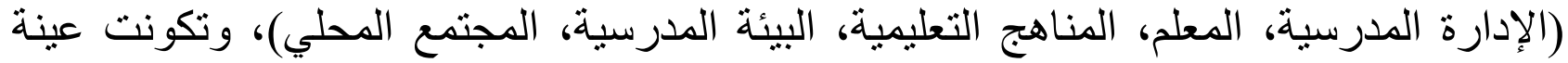
الدارسة من(215) مدير مدرسة حكومية.

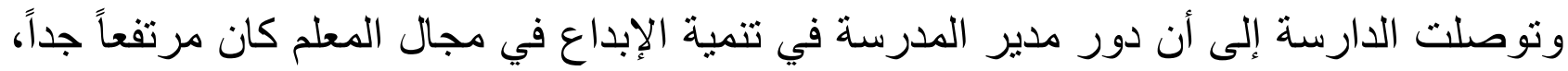

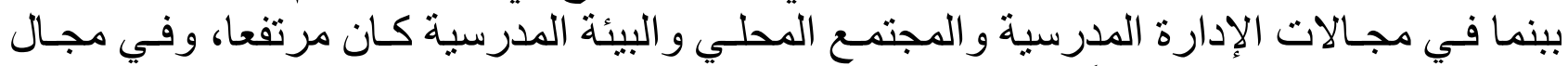
المناهج الدر اسية كان منوسطاً.

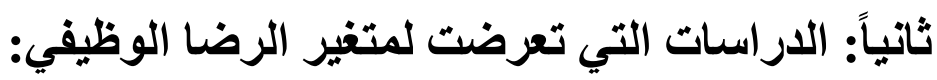

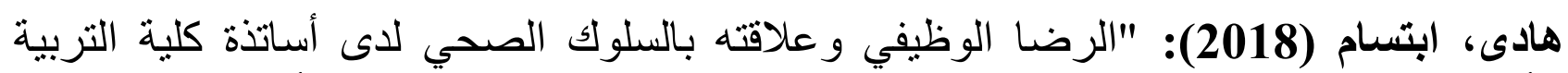

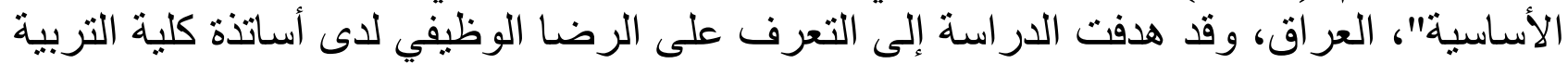

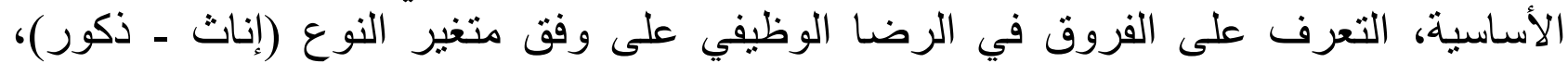

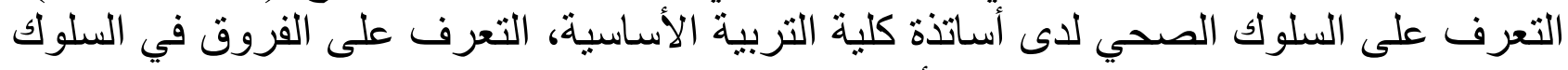

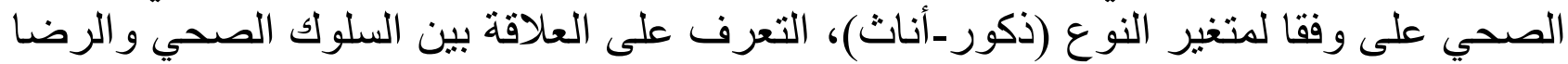

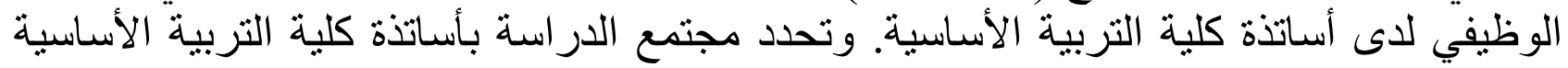

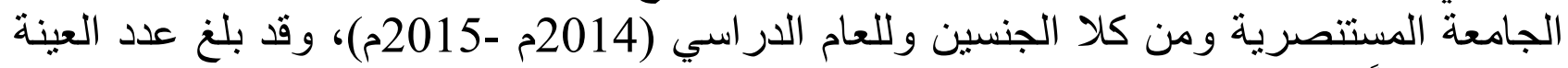

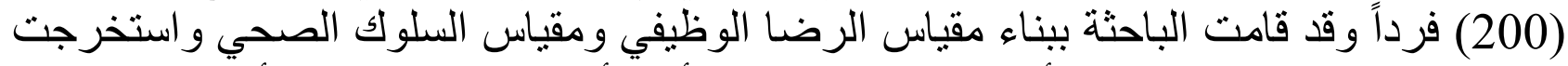

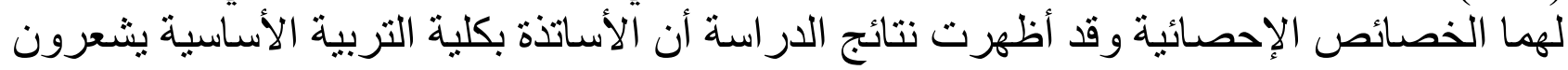

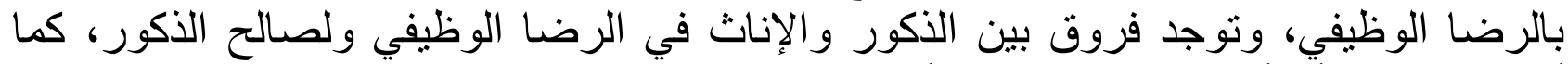

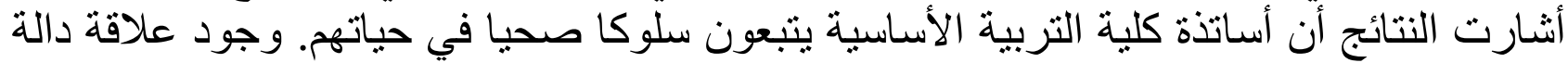

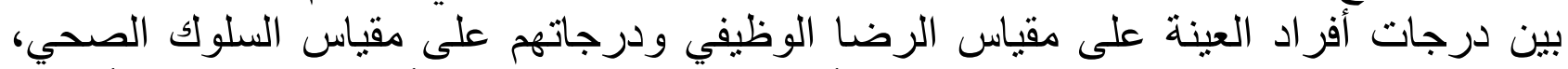

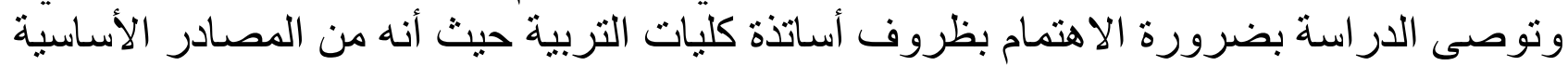

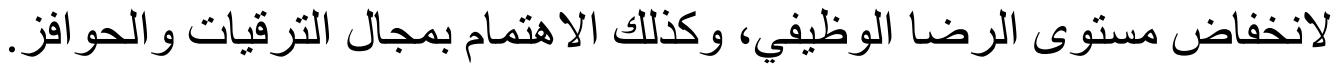

الرئ Msuya

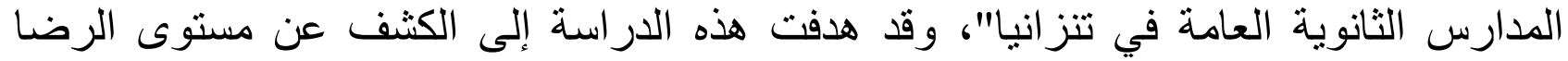

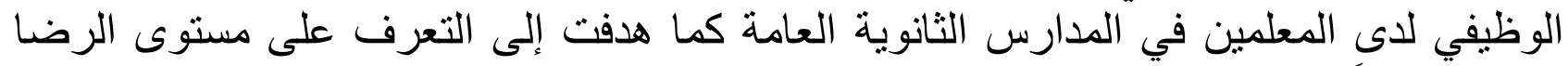

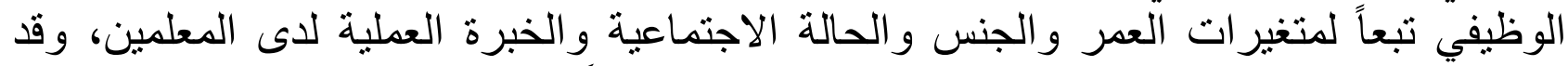

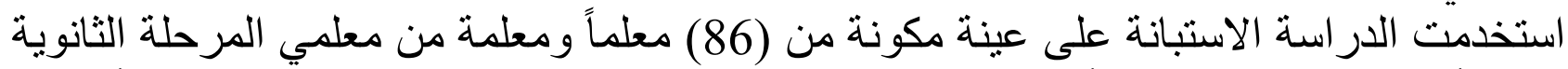

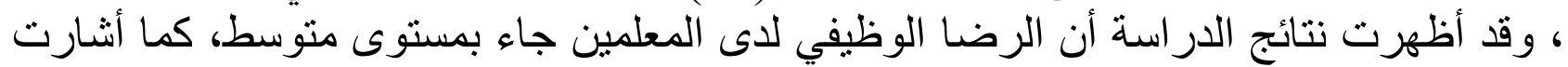

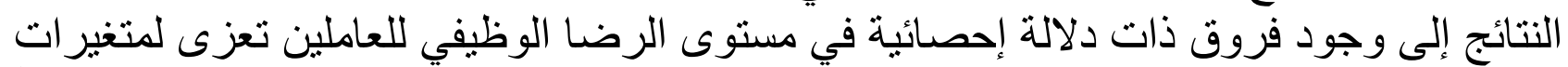

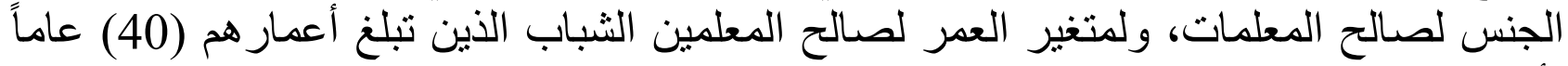

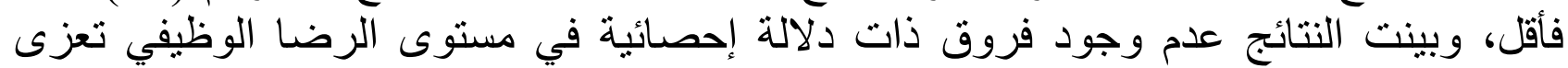

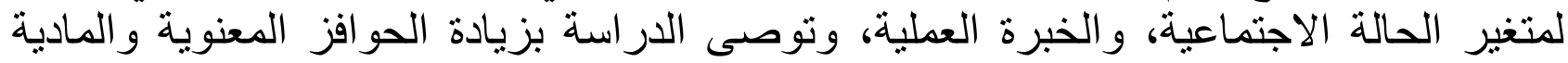


وكذللك القيام بتسهيل تدريب مديري المدارس أثناء الخدمة لرفع كفاءتهم المهنية و أدائهم لكى بساعد على زيادة مستوى الرضا الوظيفي لديهم.

دراسة الكندي (2014) عنوانها: "الرضنا الوظيفي لدى المعلمين الوافدين في مدارس التعليم الأساسي بمحافظة الداخلية في سلطنة عمان"، هدفت إلى التعرف على مستوى الرضى الريا الوظيفي لاىى المعلمين الوافدين بمحافظة الداخلية بسلطنة عمان، وقد استخدم الباحث في دراسته المنهج الوصفي، كما اعتمد الاستبانة وتم تطبيقها على عينة الوافدين المكونة من (200) معلماً ومعلمة بمدارس التعليم الأساسي بمحافظة الداخلية. توصلت نتائج الدراسة إلى أن مجال التنمية المهنية

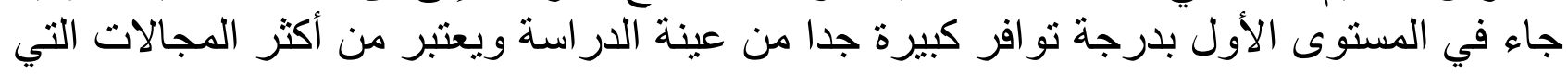
تو افق الرضا الوظيفي لدى المعلمين الوافدين من وجهة نظر عينة الدراسة، بينما جاء مجال

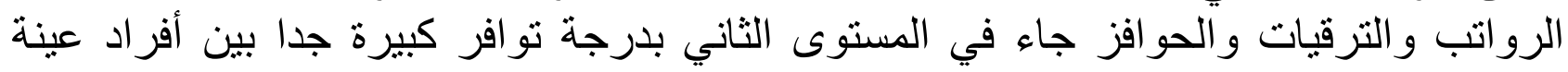
الدر اسة، وجاء مجال التفكير في الوطن في المستوى الثالث، في حين جاء مجال مقر السكن في

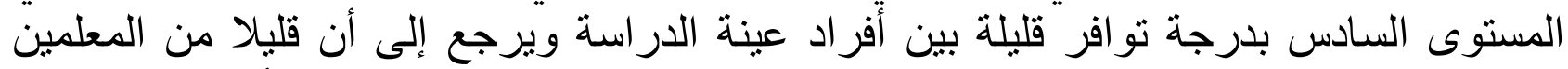

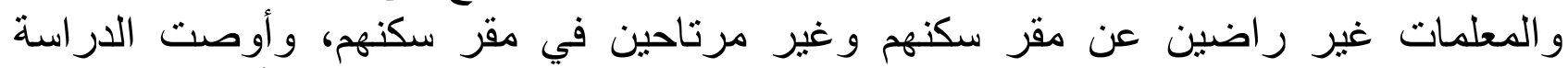

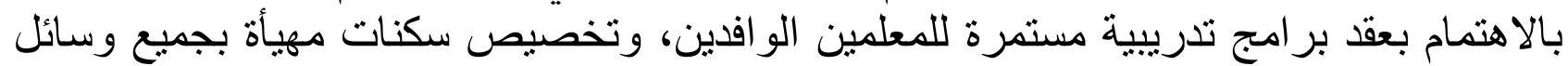
الخدمة التي تتيح الراحة للمعلم الوافد مع فتح شبكة معلوماتبة سربعة وكذلك عقد لقاء تربوي

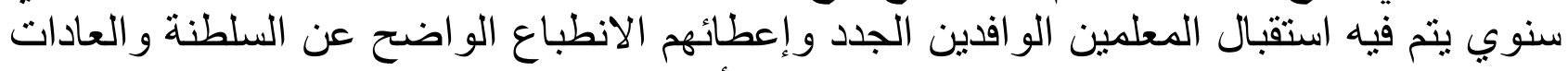
و التقاليد و القيم و المبادئ و عدم المساس بها و التقبد بالأنظمة و القو انين.

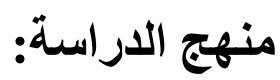

بغرض تحقيق أهداف الدراسة والإجابة أسئلتها، فقد اعتمد الباحث المنهج الوصفي، وذلك من خلال تحديد مستوى حل المشكلات بطريقة إبداعية ومستوى الرضا الوظيفي لمديري مدارس التعليم ما بعد الأساسي.

منهج البحث الوصفي الارتباطي وكذلك لتحديد نوع العلاقة ما بين حل المشكلات إبداعيا و الرضا الوظيفي وقوتها، و التعلاقة بين الرضا الوظيفي و المتغير ات الثخصية (الجنس - الخبرة ـ المؤهل التعليمي - الحالة الاجتماعية) للمدر اء مدارس التعليم ما بعد الأساسي في محافظة شمال الباطنة بسلطنة عمان.

مجتمع الدراسة:

تكون مجتمع الدراسة من جميع القيادات الإدارية (مدراء المدارس) في المدارس الحكومية

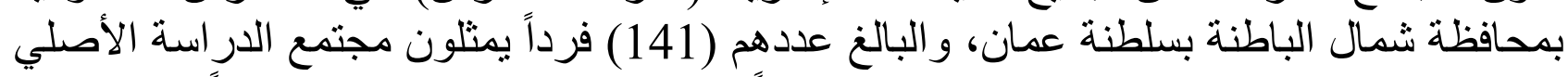

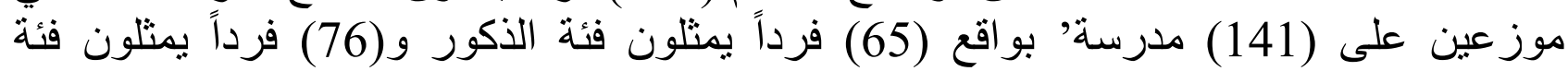
مدارس الإناث، وذلك وفقا للإحصاء الاستقرائي الصادر عن عن وزارة التربية والتعليم بسلطنة عمان

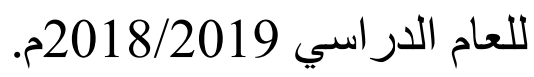

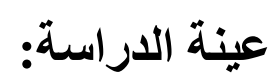

تكونت عينة الدراسة من (39) مديراً ومديرة من مجتمع الدراسة الأصلي، بعد استبعاد العينة

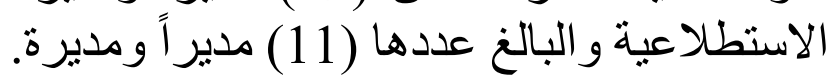


أداة الدراسة:

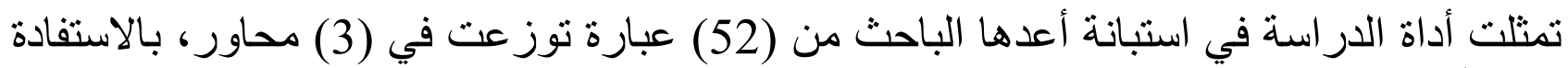

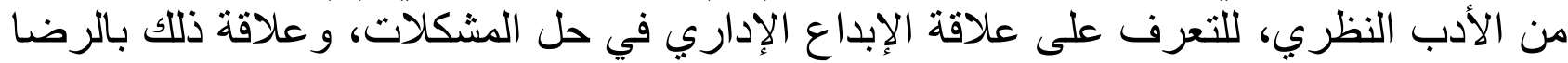

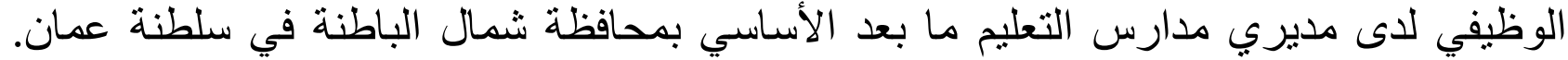

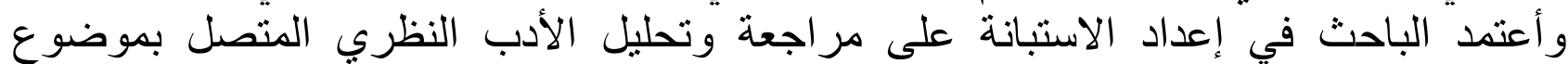

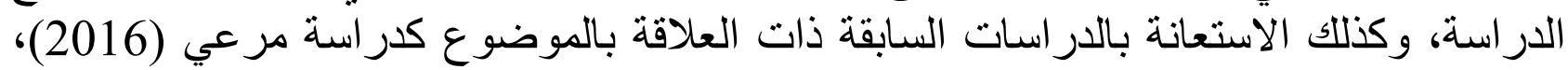

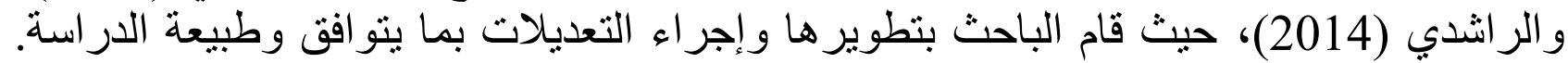
بمر اعاة الدقة والوضوح في صياغة فقرات الاستبانة وتجنب استخدام عبار ات غامضة الإنة، مما يسهل على الفرد الإجابة عليها.

نتائج الاراسة:

وللوقوف على مشكلة الدراسة بشكل منهجي قام الباحث باستطلاع آراء عدد (39) من مدراء المؤسسات والموظفين في المدارس الحكومية والخاصة بمحافظة شمال الباطنة كما يوضحها التها

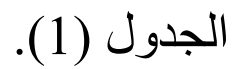

جدول (1) بيانات استطلاع الآراء

\begin{tabular}{|c|c|c|}
\hline النسبة المئوية & العدد & المتغيرات \\
\hline & & النوع الاجتماعي \\
\hline$\% 43.6$ & 17 & 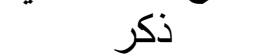 \\
\hline$\% 56.4$ & 22 & أنثى \\
\hline$\% 100$ & 39 & القطاعوع \\
\hline$\% 76.9$ & 30 & حكومي \\
\hline$\% 23.1$ & 9 & خاص \\
\hline$\% 100$ & 39 & الوظيفوة \\
\hline$\% 30.8$ & 12 & مدير \\
\hline$\% 69.2$ & 27 & موظف \\
\hline$\% 100$ & 39 & المجموع \\
\hline
\end{tabular}

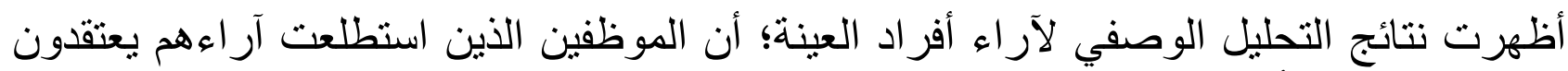

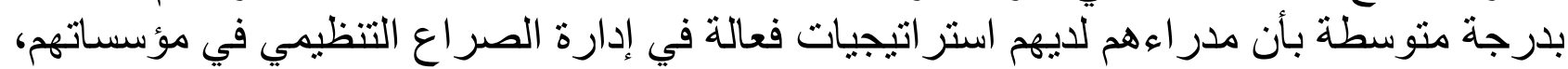

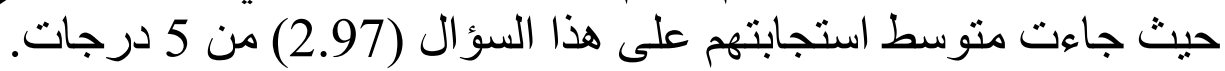

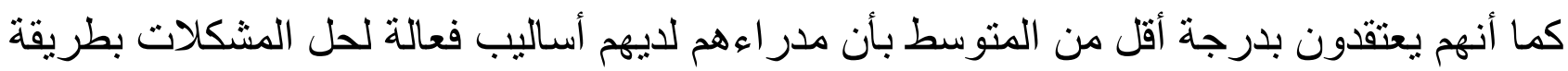

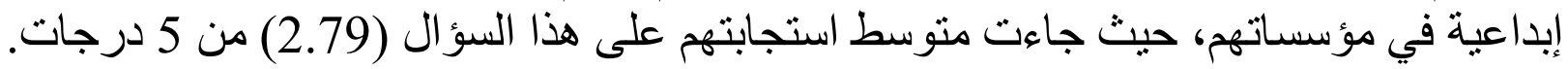

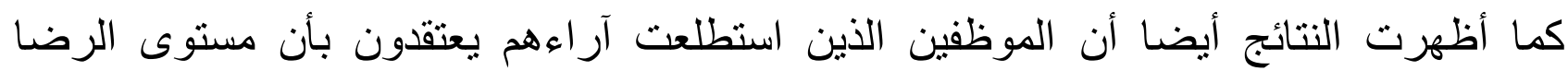

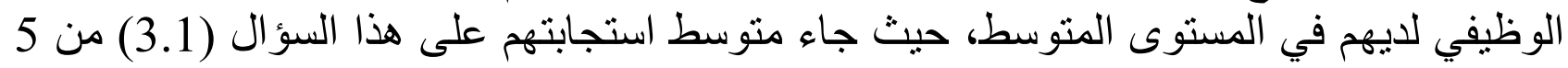
درجات. كما يوضحه الجدول (2). 
جدول (2) متوسط استجابات العينة حول مستوى الصراع التنظيمي والأساليب الإبداعية لحل المشكلات ومستوى الرضا الوظيفي

\begin{tabular}{|c|c|c|c|}
\hline الانحر اف المعياري & المتوسط الحسابي & العدد & المتغيرات \\
\hline 1.34726 & 2.9744 & 39 & مستوى الصر اع التنظيمي \\
\hline 1.21784 & 2.7949 & 39 & مستوى أساليب حل المشكلات بطريقة إبداعية \\
\hline 1.04617 & 3.1026 & 39 & مستوى الرضا الوظيفي \\
\hline
\end{tabular}

ومن جانب آخر، قام الباحث بتحليل استجابات أفراد العينة باستخدام معامل بيرسون للارتباط الراط،

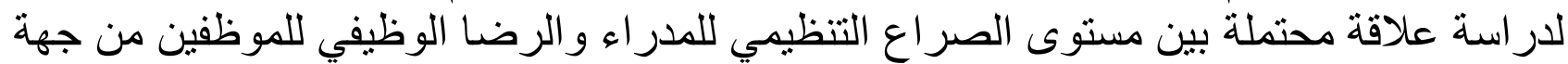

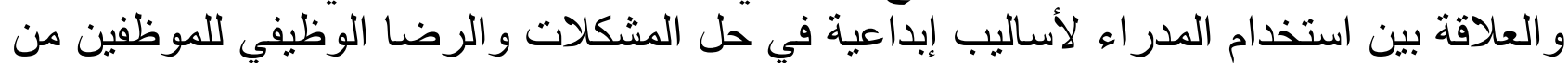

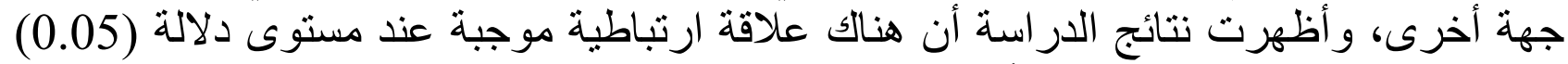

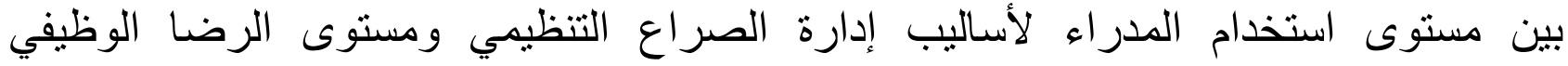

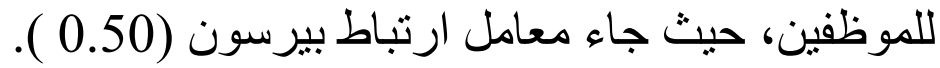

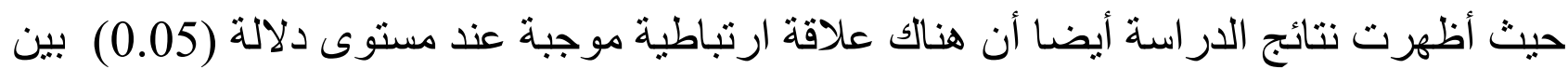

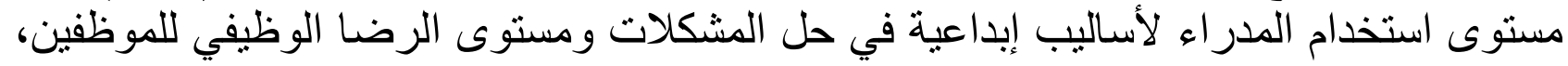

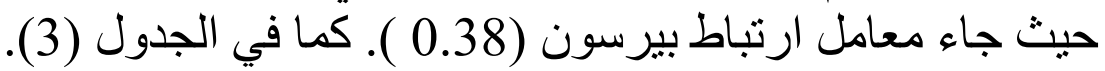
جدول (3): معامل ارتباط بيرسون

\begin{tabular}{|c|c|c|}
\hline الرضا الوظيفي & & المتغيرات \\
\hline 0.50 & معامل بيرسون & \\
\hline 0.01 & مستوى الدلالة & إدارة الصر اع التنظيمي \\
\hline 39 & العدد & \\
\hline 0.38 & معامل بيرسون & \\
\hline 0.01 & مستوى الدلالة & أساليب حل المشكلات \\
\hline 39 & العدد & \\
\hline
\end{tabular}

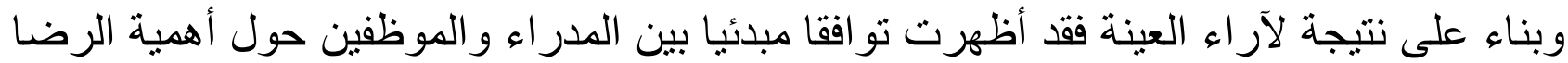

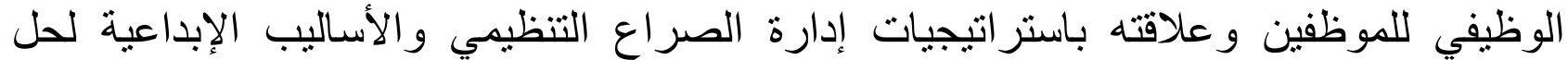

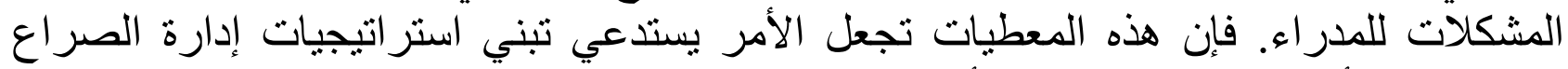

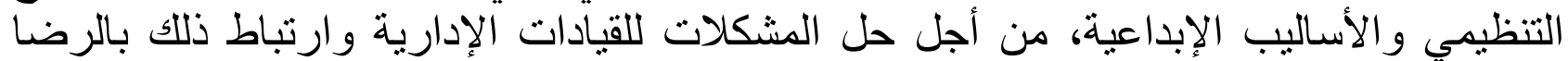

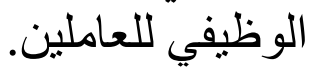

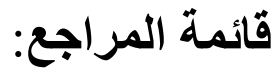
ابن منظور، أبو الفضل جمال الدين (2003): لسان العرب، ج 15, بيروت: دار صادر.

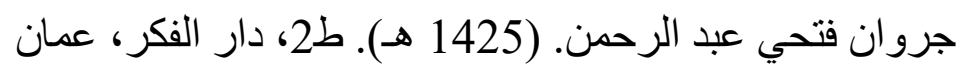
الدهان، أميمة، (1992م). نظريات منظمات العمل، المو هبة و التفوق و الإبداع عمان.

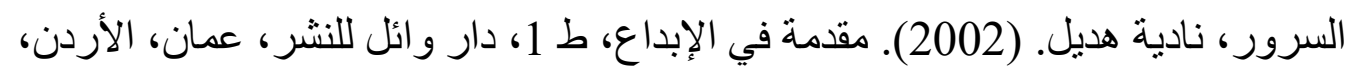


السكارنة، بلال خلف (2011). الإبداع الإداري ط 1. الأردن: دار المسيرة للنشر و التوزيع و الطباعة.

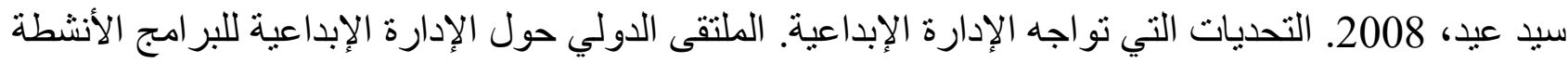

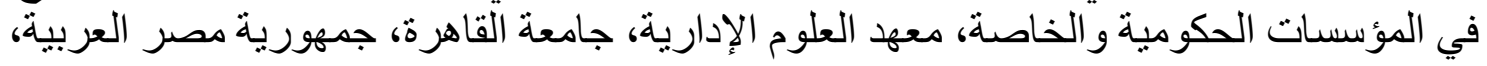
شاويش, مصطفى نجيب. ( 2011) -إدارة الموارد البشرية-, دار الشروق, عمان, الأردن.

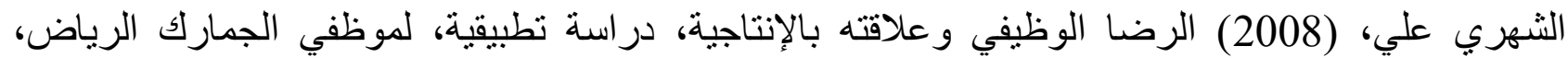
مأجستير، الرياض، المملكة العربية السعودية.

الثيخ، سوسن سالم (1997). در اسة النّموذج الإسلاميّ للرضا الوظيفي "نموذج مقتر ح"، المجلة الْعربية بكلية

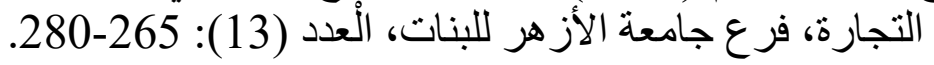

العديلي، ناصر تحمد (1414هـ)، إدارة السلوك التنظيمي، الرياض، مر ام للطباعة الإلكترونية.

العطيات، ححم يوسف النمرات، (2006 م)، إدارة التغيير والتحديات المعاصرة للمدير رؤية معاصرة لمدير الفرن الحادي و العشرين، بحث منشور في كتاب، ط1، دار، دار الحامد للنشر، عمان.

فضل الله، فضل الله. (1406 هـ). المقومات السياسية والاقتصادية والاجتماعية والثقافية في العالم العربي و أثرها في توجهات الإبداع الإداري.

نصر عزة جلال : الإبداع الإداري و التجديد الذاتي للمدرسة الثانوية العامة - رؤية إستر اتيجية ،

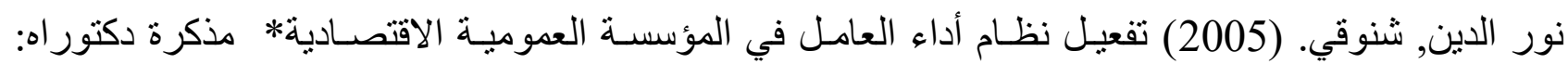

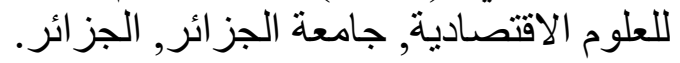

هيجان، عبد الرحمن أحمد (1999م)،. المدخل الإبداعي لحل المشكلات، الرياض، أكاديمية نايف العربية للعلوم

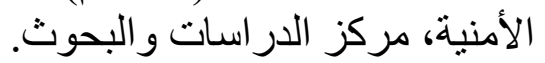

هيجان، عبد الرحمن أحمد. (1420 هـ). معوقات الإبداع الإداري في المنظدات السعودية. مجلة الإدارة العامة،

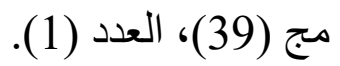
و هيبة، غراري. (2010 ). *الإدارة الحديثة للمكتبات* الديوان الوطني للمطبو عات الجامعية، الجرائر.

\section{ARABIC REFERENCES IN ROMAN ALPHABET}

Abn Munzur, 'Abu Alfadl Jamal Aldiyn (2003): Lisan Alearab, J 15, Biruta: Dar Sadr. Jurwan Fathi Eabd Alrahmn. (1425 H). T2, Dar Alfikr, Eamman

Alduhan, 'Amimat, (1992ma). Nazriaat Munazamat Aleaml, Almawhibat Waltafawuq Wal'iibdae Eamaan. Alsrur, Nadiat Hdyl. (2002). Muqadimatan Fi Al'iibdae, T 1, Dar Wayil Lilnashr, Eaman, Al'urdunn Alsakarnat, Bilal Khalf (2011). Al'iibdae Al'iidaria T 1. Al'urduna: Dar Almasirat Lilnashr Waltawzie Waltabaeati. Syd Eayd, 2008. Altahadiyat Alty Tuajih Al'iidarat Al'iibdaeiata. Almultaqaa Alduwalia Hawl Al'iidarat Al'iibdaeiat Lilbaramij Al'anshitat Fi Almuasasat Alhukumiat Walkhasati, Maehad Aleulum Al'iidariati, Jamieat Alqahirat, Jumhuriat Misr Alearabiat,

Shawish, Mustafaa Najib. (2011) -'Iidarat Almawarid Albshryt-, Dar Alshrwq, Eaman, Al'urdunn.

alshahriu eali, (2008) alrada alwazifiu waealaqatuh bial'iintajiati, dirasat tatbiqiatin, limuazafi aljamarik alriyadi, majstir, alriyadi, almamlakat alearabiat alsaeudiat.

alshiykhu, susin salim (1997). dirasat alnnmwdhj al'islamy lilrada alwazifii "nmudhj muqtarh", almajalat alerbyt bikuliat altijarati, fare jamieat al'azhar lilbanati, aledd (13): 265-280.

Aleadiliu, Nasir Muhamad (1414h), 'lidarat Alsuluk Altanzimii, Alriyadi, Maram Liltabaeat Al'iiliktruniat.

Aleutayatu, Muhamad Yusif Alnumarati, (2006 Ma), 'lidarat Altaghyir Waltahadiyat Almueasirat Lilmadir Ruyat Mueasarat Limadir Alfurn Alhadi Waleishrina, Bahathi Manshur Fi Kitab, Ta1, Dar Alhamid Lilnashr, Eaman. 
Fadal Allah, Fadal Allh. (1406h). Almuqawimat Alsiyasiat Walaiqtisadiat Walaijtimaeiat Walthaqafiat Fi Alealam Alearabii Wa'athariha Fi Tawajuhat Al'iibdae Al'iidari. Nasr Eizat Jalal : Al'iibdae Al'iidarii W Altajdid Aldhdhatia Lilmadrasat Alththanawiat Aleamat - Ruyatan 'listratijiatan ,

Nur Aldiyn, Shanuqi. (2005) Tfaeayl Nazam 'Ada' Aleaml Fi Almusast Aleamumit Alaqtsadyt, Mudhakirat Dukturah: Lileulum Alaiqtisadiat, Jamieat Aljazayira, Aljazayir.

Hayajan, Eabd Alruhmin 'Ahmad (1999m), Almudkhil Al'iibdaeiu Lihali Almushkilati, Alriyadi, 'Ukadimiat Nayif Alearabiat Lileulum Al'amniati, Markaz Aldirasat Walbuhuth.

Hayajan, Eabd Alruhmin 'Ahmid. (1420h). Mueawiqat Al'iibdae Al'iidarii Fi Almunazamat Alsaeudiati. Majalat Al'iidarat Aleamati, Maj (39), Aleadad (1).

Wahibati, Gharari. (2010). ${ }^{*}$ Al'iidarat Alhadithat Lilmukatibati* Aldiywan Alwatanii Lilmatbueat Aljamieiati, Aljarayir.

\section{REFERENCE LIST}

Nurul Kabir, M.M. (2011) Factors Affecting Employee Job Satisfaction of Pharmaceutical Sector, Australian Journal of Business and Management Research,1, (9): P115. 